\title{
Análisis geoarqueológico de las ocupaciones musterienses en el valle alto del río Eresma: el Abrigo del Molino (Segovia, España)
}

\author{
D. Álvarez-Alonso(1), M. de Andrés-Herrero(2), A. Díez-Herrero ${ }^{(3)}$ y J.A. Rojo Hernández ${ }^{(4)}$ \\ (1) Departamento de Prehistoria y Arqueología. UNED/Centro Asociado de Asturias, \\ Avda. Jardín Botánico 1345 (Calle interior), E-33203 Gijón, España \\ dalvarez@gijon.uned.es \\ (2) Instituto de Arqueología Prehistórica. Universidad de Colonia (Alemania) / Museo Neanderthal, \\ Talstraße 300, D-40822, Mettmann, Alemania \\ mdeandres@neanderthal.de \\ (3) Departamento de Investigación y Prospectiva Geocientífica, Instituto Geológico y Minero de España (IGME), \\ Ríos Rosas 23, E-28003, Madrid, España \\ andres.diez@igme.es \\ (4) Departamento Prehistoria y Arqueología, UNED, Paseo Senda del Rey 7, E- 28040, Madrid, España \\ julio.a.rojo@gmail.com
}

\begin{abstract}
RESUMEN
Hasta 2012, la ausencia de investigaciones arqueológicas sistemáticas en el alto valle del Eresma, hacía que esta área fuera considerada como un vacío ocupacional durante el Paleolítico. En este trabajo se presentan los primeros resultados del proyecto 'Primeros Pobladores de Segovia', cuyo enfoque geoarqueológico ha permitido, no sólo el descubrimiento de yacimientos musterienses como el Abrigo del Molino, sino la contextualización de las primeras ocupaciones humanas de esta zona del valle del Eresma desde un punto de vista cronocultural y paleoambiental. Sin duda, las excavaciones realizadas en este yacimiento son la principal fuente de información para este análisis. Además, los nuevos resultados obtenidos fruto de las excavaciones en la zona superior del Abrigo del Molino, en la recientemente descubierta cueva de San Lázaro y en las prospecciones realizadas en esta área, están aportando nueva información sobre la interpretación geoarqueológica de las primeras ocupaciones humanas en el valle alto del río Eresma.
\end{abstract}

Palabras clave: Cuenca del Duero, Geocronología, karst, Paleolítico medio, Sistema Central Español.

\section{Geoarchaeological analysis of Mousterian settlements in the upper part of the Eresma river valley: Abrigo del Molino (Segovia, Spain)}

\begin{abstract}
The absence of systematic archaeological investigations in the upper part of the Eresma River valley has resulted in this area being considered as an empty space during the Palaeolithic. This paper presents the first results of the project the 'First Settlers of Segovia', where the geoarchaeological approach has not only allowed the discovery of Mousterian sites such as the Abrigo del Molino, but has also allowed the contextualization of the first human occupation of this area of the Eresma River valley from a chrono-cultural and paleoenvironmental point of view. Undoubtedly, the excavations at this site are the main source of information for this analysis. Furthermore, new results obtained during the excavations in the upper part of Abrigo del Molino and in the recently discovered site of the San Lázaro cave, together with the data of the surveys performed in this area are also providing new information on the geoarchaeological interpretation of the first human occupations in the upper part of the Eresma River valley.
\end{abstract}

Key words: Duero basin, Geochronology, karst, Middle Palaeolithic, Spanish Central System. 
Álvarez-Alonso, D., et al., 2018. Análisis geoarqueológico de las ocupaciones... Boletín Geológico y Minero, 129 (1/2): 153-182

\section{ABRIDGED ENGLISH VERSION}

\section{Introduction and methods}

In contrast to the situation in other neighbouring areas, the upper part of the Eresma River valley has not been systematically investigated to analyze their Paleolithic settlements. In 2012, we started our research in this area by developing archaeological surveys in the framework of our research project. As a result of these studies we found the Abrigo del Molino (Álvarez Alonso et al., 2013a), a Mousterian site located in the centre of the Iberian Peninsula between the Duero valley and the Spanish Central range (Figs. 1, 2 and 3).

First of all, this paper presents the progress made on the geoarchaeological analysis of the site carried out during the last two archaeological seasons, giving new data on its stratigraphic sequence, archaeological findings and its chrono-cultural framework. The geoarchaeological analysis of the Abrigo del Molino was based on stratigraphic readings, taking into account the documentation of horizontal structures, during the progression of excavations (Goldberg and Macphail, 2006). The analysis of the infillings was essentially focused on the characterization and analysis of the sedimentary deposit and a sedimentological and micromorphological analysis. Regarding the horizontal analysis by excavation surfaces, special attention was paid to the identification of the dip of the levels and the presence of clasts, as far as their preferred arrangement, size and morphology was concerned. For the archaeological material, the topography of every piece was established. In addition, its dip and position was recorded in relation to the major axis of every piece (bone or lithic), so as to complete the analysis of the archaeological levels and provide key information for interpreting the archaeological layers. In addition, a total of 4 samples from units $D, E, G$ and $M$ of the detrital sediment filling the shelter were taken for optically stimulated luminescence (OSL) dating.

Secondly, we present the first results of the environmental analysis conducted in the surroundings of the Abrigo del Molino. Although this study is at an early stage, archaeological surveys and excavations have allowed us to identify new Palaeolithic evidence in the vicinity of the site. The description of the physical and geological environment of the upper part of the Eresma River valley and the creation of a Geographic Information System (GIS) for its analysis are also some of the elements that are being used to complete the vision of the first human groups that occupied this territory. Furthermore, surveys are being conducted to find the procurement areas of raw materials, and these first results are also shown in this paper.

\section{Results and discussion}

The Abrigo del Molino consists of a shallow cave of fluvio-karstic origin, which has been completely filled in with detrital deposits (Figs. 4, 5 and 6). The geoarchaeological interpretation of its genesis differentiates three groups: a lower group with sandy loams and fine sands interbedded with pebble and gravel layers deposited by palaeo-floods and slope contributions respectively; a middle group with massive silts and grain-supported boulders, formed by alternating contributions from the overlying slope as well as karst mudflows and rock fall from the shelter roof; and an upper group of silt cemented by carbonates, final backfill alteration and degradation of the host rock (Figs. 7, 8 and 9). The techno-typological characteristics of the lithic assemblage confirm the existence of Mousterian levels at the site (Fig. 10), and OSL dating of these levels measured at the Nordic Laboratory for Luminescence Dating in Ris $\varnothing$, provided an age range of 31-60 ka for the detrital deposits (Table 1), presenting for the first time the occupation of Neanderthal groups in karstic contexts in the northern Iberian plateau, in the southern part of the Duero basin.

Furthermore, the Abrigo del Molino presents some exceptional singularities. First of all, the deep stratigraphic sequence, more than $4.5 \mathrm{~m}$ in total, is quite uncommon in endo-karstic environments. Secondly, there are a large number of different lithological levels, more than 15, and, thirdly, the site yielded a huge range of detrital textures, from clays to boulders comprising silts, sands and gravels. They are complemented by numerous paleo-environments and sedimentary genesis models, both in endokarstic and exokarstic facies (Campaña et al., 2013); and finally, the presence of extremely singular sedimentary sequences (at least two levels of slack water deposits, i.e. paleo-flood eddy bars) (Benito et al., 2003). Archaeological remains demonstrate that the rock shelter was occupied by Neanderthal groups at three different moments: levels 2 and 3 and unit K. The analysis of the "chaînes opèratoires" in levels 2 and 3 present many similarities especially in knapping methods, dominated by discoid and Levallois operational systems. The identified toolkit comprises few pieces, essentially denticulates and notches, with a high presence of choppers. Concerning faunal remains it is important to highlight that although bone preservation can be considered excellent, the taxonomic identification is difficult due to the high fragmentation of the bones and the lack of teeth and epiphysis in the record. Nonetheless, it was possible to confirm the presence of Equus sp. and Cervus elaphus, in levels 2 and 3. There is also a large variability of raw materials in the lithic industry (granitoids, metamorphic rocks, many quartz varieties, flint, jasper, chalcedony, etc.), most of them are easily found in the alluvial 
Álvarez-Alonso, D., et al., 2018. Análisis geoarqueológico de las ocupaciones... Boletín Geológico y Minero, 129 (1/2): 153-182

deposits of the Eresma river. However, the provenience of some of the siliceous materials used at the site suggests more complex mobility and procurement strategies, where a preferential use of the site surroundings and a medium- and long-distance logistical planning within a wider territory would be combined. All these characteristics, and the exceptional preservation, form a singular and attractive archaeological site from a geoarchaeological point of view, essential for understanding the Neanderthal population in southwestern Europe.

Previous to the discovery of the Abrigo del Molino, the area between the Duero valley and the Central System was presented as a region with limited Neanderthal habitats. Just one Mousterian open-air site is fully recognized in the area, the Estación (Álvarez Alonso and Andrés Herrero, 2011a, 2011b, 2014). Furthermore, the only Palaeolithic remains found in the Eresma river valley were limited to the Acheulean site of Armuña and some other isolated findings with similar chronology documented on the terraces of the middle part of Eresma basin. New archaeological excavations and surveys developed during 2013 allowed us to discover new Palaeolithic traces in this area. First, we also found another rock shelter in the upper part of the Abrigo del Molino that was also completely filled with sediments. A small test pit was developed showing evidence of human occupation: faunal remains with cut marks and scarce lithics that could be preliminary linked with the Abrigo del Molino (Fig. 11).

In the same bank of the Eresma River, we also found the cave of San Lázaro where abundant faunal remains and a lithic assemblage formed by side-scrapers and of evidence of Levallois technique were found (Fig. 12).We have also found other archaeological remains in open air contexts which are probably related with a Lower Palaeolithic occupation (Fig. 13).

The geoarchaeological research in the Abrigo del Molino presents a rich sequence of levels that covers substantially all OIS 3, including three levels with human occupation. These results are of great value for analyzing the end of Neanderthal human occupations in the interior of the Peninsula and to obtain contextual data which can help us to establish a chronostratigraphy in the terraces of the upper part of the Eresma River valley, thanks to the palaeo-flood levels documented in the basis of the sequence (Díez Herrero et al., 2014). Currently, the Abrigo del Molino and their three occupational horizons may be related to other sites in the northern Iberian plateau, inasmuch as sites in the southern area of the Central range -Pinilla del Valle sites (Baquedano et al., 2014), Jarama VI (Jordá Pardo et al., 2014) or even Los Casares (Barandiarán, 1969) and Peña Cabra (Alcolea et al., 1997) may be related. It defines a new habitat space which is becoming increasingly important in central lberia.

The chrono-cultural and geochronological sequence of the Abrigo del Molino, together with other Palaeolithic findings in its surroundings, which were uncovered in the course of our research, will allow us to deepen the study of the physical and environmental evolution of the Eresma River valley. Although paleoenvironmental data are scarce, they can also be correlated with the information provided by the paleontological sites located in the area (Búho-Zarzamora, Pinarillo l, etc.), showing one of the most complete sequences for performing a palaeogeographical interpretation in Central Iberia.

\section{Introducción}

Este trabajo se centra en la presentación del análisis geoarqueológico y cronoestratigráfico del yacimiento musteriense del Abrigo del Molino, junto con el resto de evidencias que sirven para contextualizar estas ocupaciones humanas en el valle alto del Eresma (Segovia).

Las investigaciones sobre las primeras ocupaciones humanas en el valle del río Eresma se caracterizan por la práctica ausencia de prospecciones sistemáticas y la inexistencia de yacimientos musterienses hasta que, en 2012, se produjo el descubrimiento del Abrigo del Molino. Este hecho contrasta con otras áreas de la península, algunas de ellas colindantes con la provincia de Segovia, como Valladolid, Madrid, Guadalajara o Soria, donde existió una mayor tradición investigadora enfocada hacia el análisis de las etapas más antiguas de la Prehistoria (Díez Martín, 2000; Rodríguez de Tembleque, 2008;
Santonja and Pérez González, 2000-2001; Barandiarán, 1969; Alcolea et al., 1997). El hecho de que la primera referencia a un asentamiento paleolítico del valle del Eresma provenga de A. Molinero (1971), refiriéndose al hallazgo aislado de un bifaz en Roda de Eresma (única mención hasta la década de 1990), constata que los estudios de este periodo en la zona, son mucho más recientes que en otras áreas peninsulares, como se ha puesto de manifiesto tras analizar las evidencias del Paleolítico inferior y medio en la parte más oriental de la provincia, entre las cuencas de los ríos Riaza y Eresma (Álvarez Alonso and Andrés Herrero, 2011b y 2014). En este sentido, la escasez de yacimientos en esta región, puede estar justificada, más que en su inexistencia, en la falta de trabajo de campo e investigaciones exhaustivas sobre el Paleolítico, no sólo en el valle del Eresma, sino en un territorio más amplio que abarca la parte sur del valle del Duero hasta alcanzar el piedemonte del Sistema Central. 
De este modo, no será hasta mediados de la década de 1990, cuando se descubre el primer yacimiento paleolítico en el valle del Eresma, el yacimiento achelense de Los Molinillos, en el municipio segoviano de Armuña (Rodríguez de Tembleque et al., 1998; Rodríguez de Tembleque, 2005 y 2008), situado al aire libre sobre la terraza $+26 \mathrm{~m}$ del Eresma. Más recientemente, a partir del año 2009 iniciamos un proyecto de investigación cuyo objetivo era analizar, desde un punto de vista geoarqueológico, las primeras ocupaciones humanas paleolíticas al sur del Duero, entre las cuencas de los ríos Eresma y Riaza (Álvarez Alonso and Andrés Herrero, 2014). En una primera fase, realizamos (DAA y MAH) prospecciones arqueológicas en la zona del interfluvio Riaza-Duratón, donde aparte de los enclaves ya conocidos, como el yacimiento musteriense de La Estación, documentamos la existencia de nuevos yacimientos al aire libre adscritos al Paleolítico inferior y medio antiguo, como Las Nazas o Prado Laguna (Álvarez Alonso and Andrés Herrero, 2011a, 2011b y 2014; Álvarez Alonso et al., 2013b).

En una segunda fase, realizamos prospecciones en la cuenca del Eresma, aportando como primer resultado el descubrimiento del Abrigo del Molino, un yacimiento musteriense situado en el valle alto del río Eresma (Álvarez Alonso et al., 2013a). Sin duda, una de las características más relevantes del Abrigo del Molino es su situación en un ambiente kárstico, ya que hasta el momento es el único yacimiento de esta cronología, en este tipo de medio entre el río Duero y el Sistema Central. En primer lugar se realizó una caracterización geoarqueológica del relleno del abrigo y se mandaron a analizar una batería de muestras de OSL al laboratorio danés de Ris $\varnothing$ (Nordic Laboratory for Luminescence Dating), que confirmaron la adscripción del yacimiento al Paleolítico medio.

En este artículo, los trabajos realizados en el Abrigo del Molino se enmarcan en un contexto más amplio, como es el valle alto del río Eresma, detallándose las condiciones geográficas y geológicas de esta área, fundamentales para comprender que se trata de un enclave óptimo para el habitat humano durante la Prehistoria. Asimismo, se exponen los últimos avances realizados en el análisis geoarqueológico de este sector del valle del Eresma, aún en una fase preliminar de su estudio.

\section{Contexto geográfico y geológico}

El río Eresma, desde su nacimiento en la vertiente septentrional de los Montes Carpetanos (parte central de la sierra de Guadarrama, Sistema Central español), hasta su confluencia con río Adaja, poco antes de desembocar éste último en el río Duero, describe en el sector centro-meridional de la Meseta Norte, un valle con dirección general sureste-noroeste, en el que se podrían diferenciar tres principales tramos de características fisiográficas muy diferentes (Fernández García, 1987; Díez Herrero and Martín Duque, 2005): alto Eresma, abarcando el nacimiento en las cumbres y su discurrir por las laderas de la sierra y el piedemonte serrano; Eresma medio, cuando atraviesa las vegas y campiñas de la cuenca sedimentaria de Valverde de Majano (valle en artesa escalonada con amplio sistema de terrazas) y el macizo de Santa María la Real de Nieva-Carbonero el Mayor (garganta); y bajo Eresma, en el sector que surca la comarca de la Tierra de Pinares (cañón o barranco encajado) (Fig. 1).

El primero de los tramos, el alto Eresma, se caracteriza por haber labrado su valle en los materiales ígneo-metamórficos proterozoico-paleozoicos de la Sierra y piedemonte cristalino (gneises, migmatitas, mármoles, granitoides), correspondientes a la zona Centroibérica del Macizo Ibérico (Fig. 2), donde el río traza gargantas y desfiladeros o valles abiertos de origen tectónico (Valsaín); y por la incisión en los materiales sedimentarios detrítico-carbonáticos de la orla mesozoica (Cretácico superior) correspondiente al sector occidental de la Rama Castellana de la Cuenca Ibérica, donde forma cañones de trazado meandriforme (hoces u hocinos). Precisamente en este último sector del alto Eresma, en el que atraviesa los materiales detrítico-carbonáticos mesozoicos del piedemonte septentrional de la Sierra de Guadarrama, que en este sector están subhorizontales o describiendo suaves relieves en cuesta (localmente plegados), el río ha formado su valle a lo largo del Cuaternario mediante sucesivas etapas de encajamiento que han alternado con formación de terrazas erosivas (replanos y hombreras de la lastra) o con depósitos discontinuos de materiales detríticos groseros (rañizos y pedregales). Solo en el fondo del valle actual se conserva un sistema de terrazas (Fernández, 1988) formado por el cauce y la llanura de inundación, y hasta tres niveles de terraza o glacis-terraza a alturas próximas a $+6 \mathrm{~m},+11 \mathrm{~m} \mathrm{y}+30 \mathrm{~m}$, que únicamente se conservan en las orillas internas de los meandros, donde la extensión lateral y zapado de los cortados rocosos no los ha desmantelado.

Previo al encajamiento y coetáneo con él, se desarrolló en las litologías carbonáticas (dolomías, calizas, margas y areniscas dolomíticas) un sistema kárstico, fundamentalmente endokárstico, formado por una amplia red de galerías y conductos. Las cavidades son de muy limitadas dimensiones (longitud hec- 


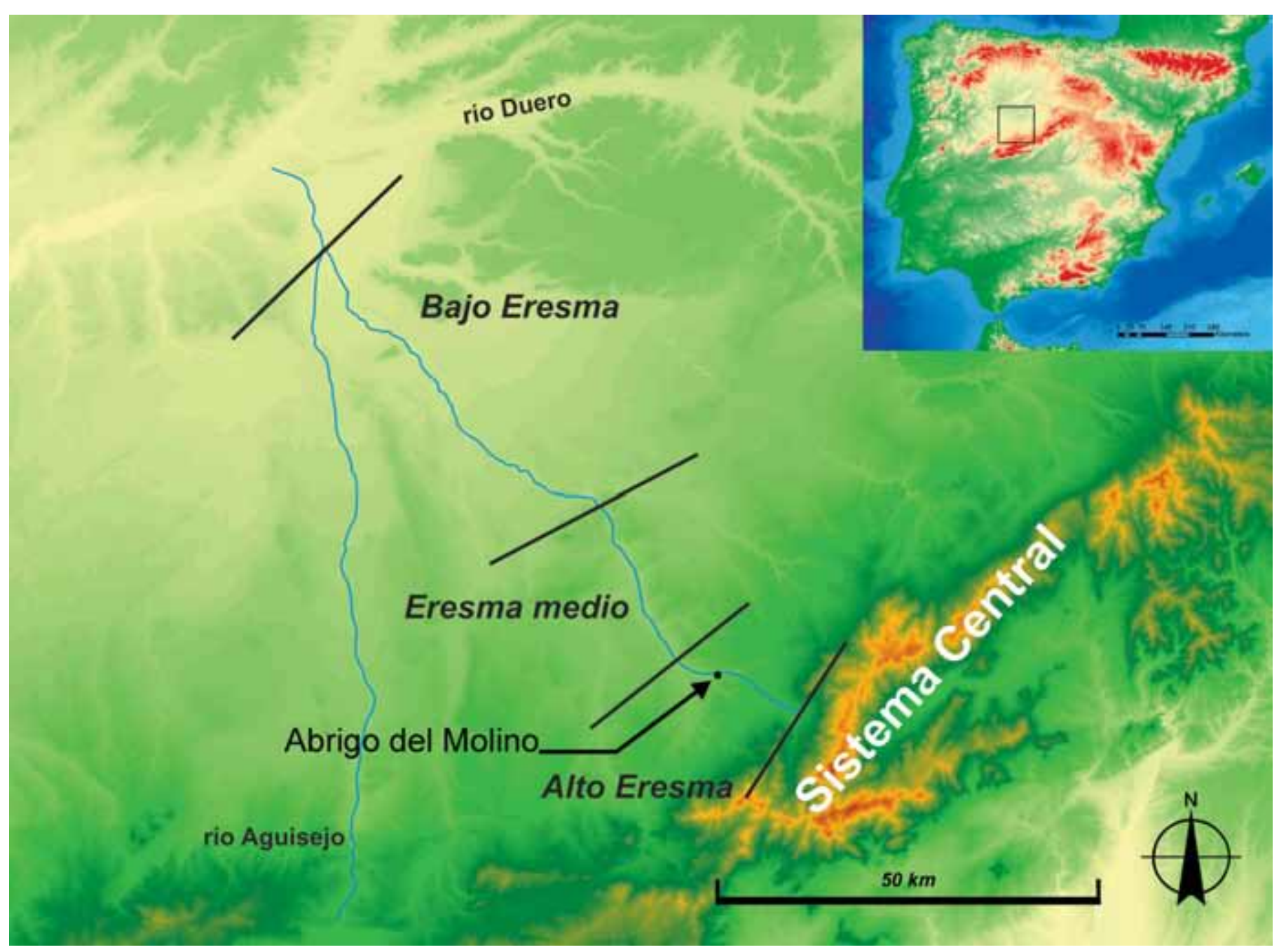

Figura 1. Mapa del valle del río Eresma, con la localización del área de estudio.

Figure 1. Map of the Eresma River valley, with the location of the study area.

tométrica y altura y anchura métrica) fundamentalmente por tres motivos: reducida disponibilidad hídrica (actual y pretérita), que limita el alcance de los procesos kársticos; escaso espesor de los bancos y estratos carbonáticos y frecuentes alternancias con otros de naturaleza más detrítica difícilmente karstificables; y rápido encajamiento del sistema fluvial, que disectó y dejó colgado y fosilizado el sistema endokárstico prácticamente en su fase freática, sin apenas desarrollo de la fase vadosa, y facilitando el relleno detrítico de las cavidades. Las cavidades que aparecen en los cortados rocosos tienen un claro control lito-estructural, concentrándose en determinados niveles carbonáticos propicios a la karstificación o en los que se concentraron etapas de estabilización en el encajamiento. Igualmente, presentan trazados que siguen direcciones de fracturación tectónica alpina (fallas, diaclasado) o aprovechan los escarpes de las cuestas y crestas de los relieves plegados. Muchos de ellos, por sus reducidas dimensiones, cabría calificarlos como balmas, abrigos y solapos, más que cuevas; y su génesis se relaciona con momentos de estabilización del encajamiento del valle y erosión lateral y zapado de las laderas por el sistema fluvio-kárstico.

En lo que respecta a la diversidad litológica como fuente de materias primas para la industria lítica, el valle del alto Eresma presenta una variedad inusitada de afloramientos de diferentes tipos de rocas: ígneas plutónicas y filonianas (granitos, granodioritas, dioritas, gabros, sienitas); metamórficas de alto grado (migmatitas, gneises, mármoles, rocas de silicatos cálcicos); y sedimentarias, tanto detríticas (lutitas, 


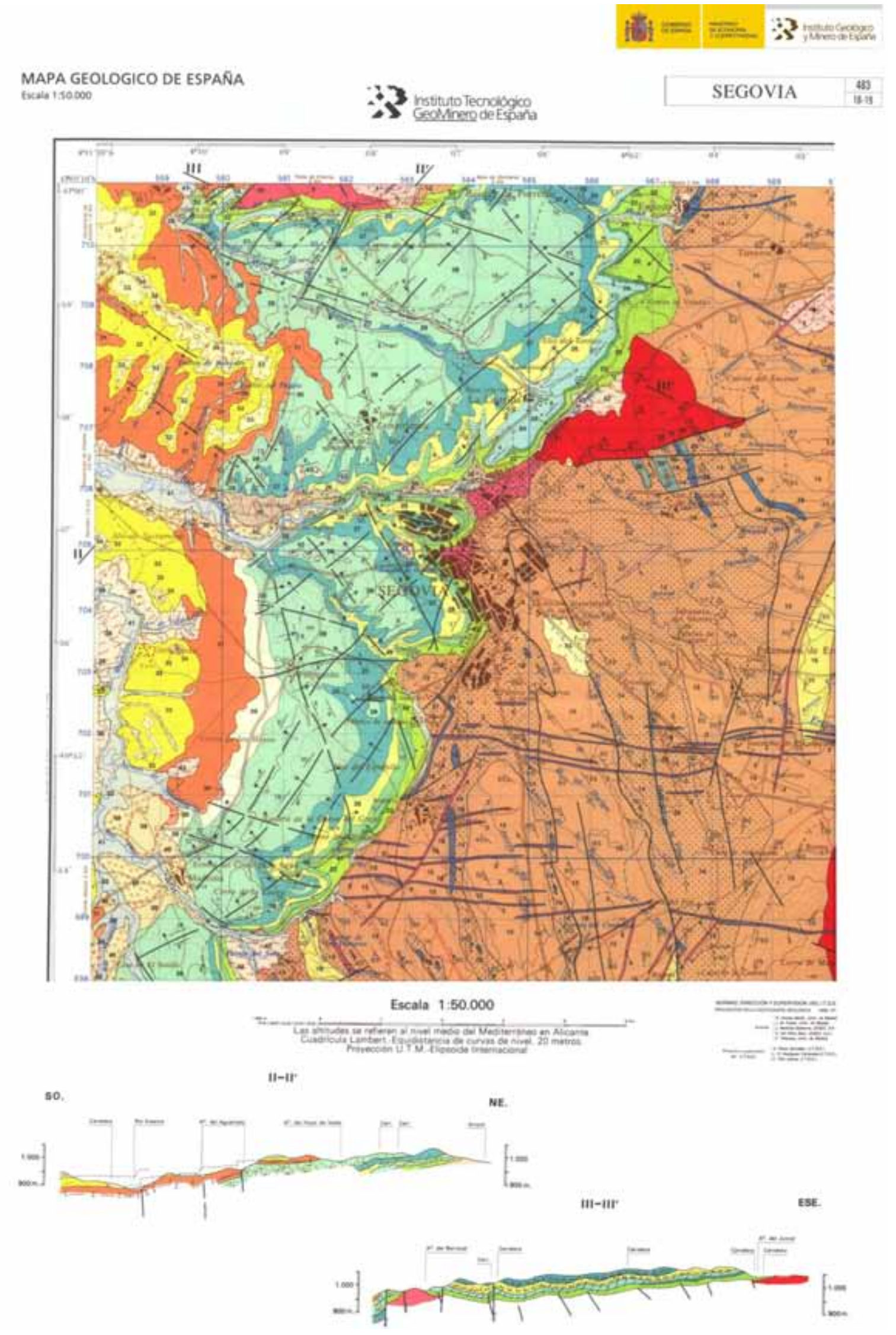


Álvarez-Alonso, D., et al., 2018. Análisis geoarqueológico de las ocupaciones... Boletín Geológico y Minero, 129 (1/2): 153-182

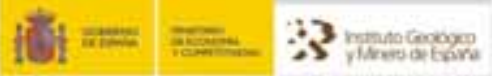

MAPA GEOLOGICO DE ESPAÑA

Escals 150.000

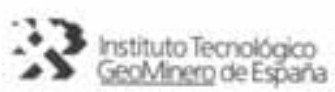

SEGOVIA
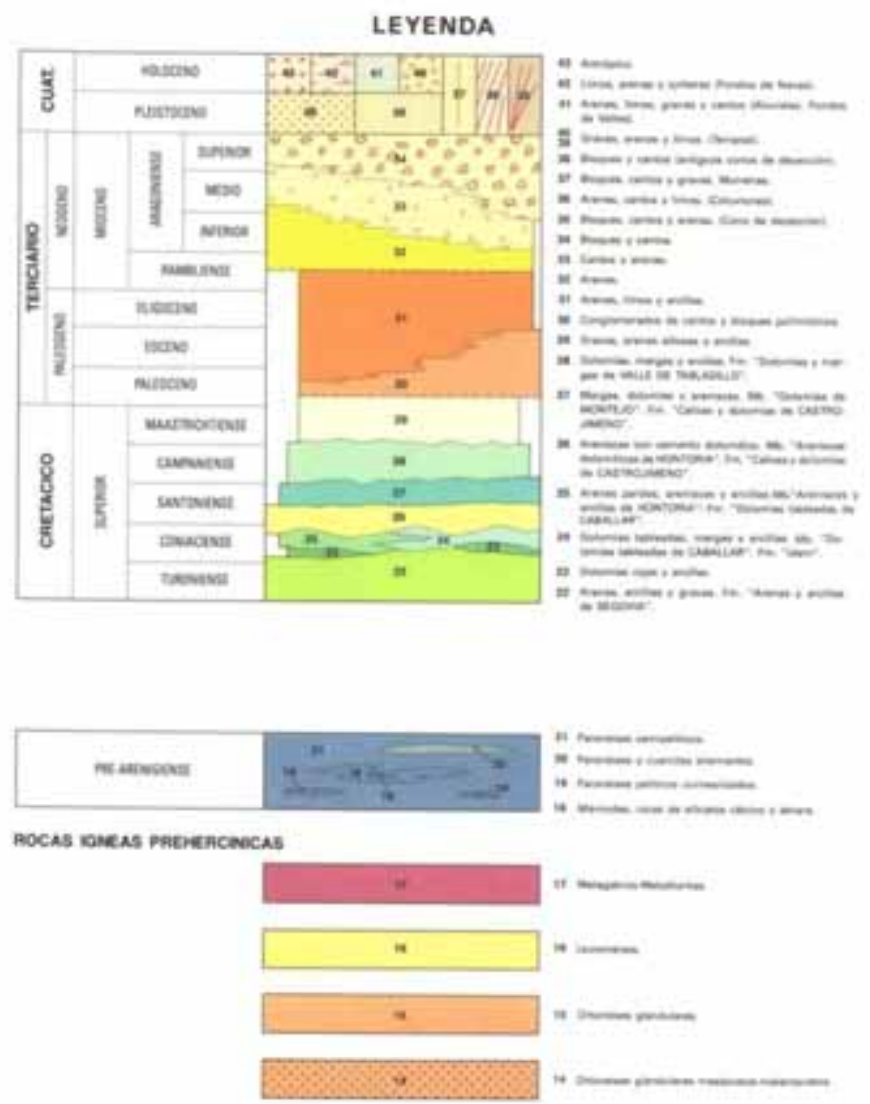

itim

" coman-

mocas chaserncas Hencracas
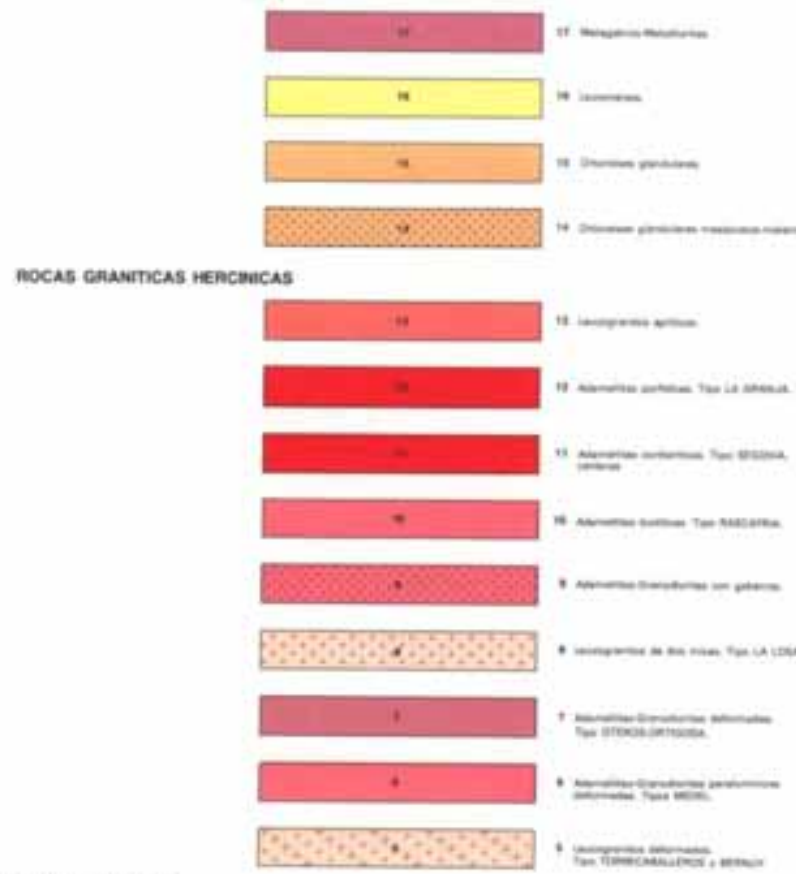

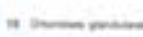

noces reovestus

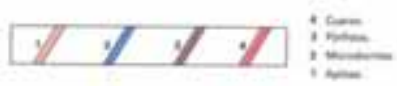

Figura 2. Mapa geológico del área de Segovia (Arenas et al., 1991).

Figure 2. Geological map of Segovia (Arenas et al., 1991). 
limolitas, areniscas, conglomerados) como carbonáticas (dolomías, calizas, margas); a lo que cabría sumar una amplia disponibilidad de minerales, fundamentalmente cuarzo (lechoso, hialino, ahumado) y variedades micro- y criptocristalinas de la sílice (calcedonia, sílex, jaspe), pero también óxidos e hidróxidos de hierro (oligisto, hematites, limonita, goethita) y manganeso (pirolusita). Además de los afloramientos de estas litologías o yacimientos minerales in situ en un radio no superior a los $15 \mathrm{~km}$, el río Eresma y su red fluvial de afluentes actúan como auténticas cintas transportadoras de fragmentos detríticos (arenas, gravas, cantos y bloques) de todas estas litologías desde la Sierra al piedemonte, por lo que las terrazas cuaternarias y el aluvial actual en los cañones calcáreos del piedemonte están compuestos por un conglomerado polimíctico granosostenido de matriz arenosa; que pone a disposición de las comunidades humanas una enorme diversidad de litologías, y además de tamaños y formas heterogéneas, de tendencia subesférica o subelipsoidal (cantos rodados) o ligeramente planares-discoidales (litologías con esquistosidad, fragmentos de diques de potencia decimétrica, o controladas por el diaclasado ortogonal), óptimas para la talla como núcleos o para su uso como percutores.

\section{Metodología}

Para llevar a cabo este estudio se ha planteado una metodología geoarqueológica siguiendo los planteamientos clásicos en esta disciplina (Goldberg and Macphail 2006) la cual se ha llevado a cabo en dos vertientes: por una parte los estudios y análisis relativos al yacimiento del Abrigo del Molino y por otro lado el análisis del entorno.

\section{Geoarqueología en el Abrigo del Molino}

El estudio geoarqueológico del Abrigo del Molino se ha realizado a partir de lecturas verticales, o estratigráficas (a) y de la documentación en horizontal, por planta (b), según se ha ido avanzando en la excavación, incluyendo la realización de distintos muestreos para la realización de diversas analíticas de índole sedimentológica y cronométrica.

El análisis estratigráfico (a) se ha centrado, principalmente, en: la caracterización y análisis del depósito sedimentario (levantamiento de columnas estratigráficas y paneles de correlación); y análisis sedimentológicos. Los métodos empleados para el levantamiento y descripción de las columnas en campo han sido los clásicos para este tipo de labores, de visu y en primera instancia: diferenciación de niveles y subniveles en base a criterios geométricos (estructura y disposición), litológicos (composición o textura), sedimentológicos (presencia o no de estructuras sedimentarias) y/o cromáticos; y descripción de los niveles, una vez perfilada la sección hacia una superficie planar lo más vertical posible.

La descripción de los niveles en el levantamiento de las columnas estratigráficas, se ha realizado en atención a los siguientes criterios:

Medición del espesor o potencia del nivel y su variación lateral en el espacio de la columna, utilizando flexómetro-jalón y flexómetros convencionales.

Descripción de los límites con las unidades inferior y superior, su carácter (brusco o gradual) y disposición geométrica (planar, convexo, cóncavo, irregular, ondulado...)

Caracterización litológica del nivel: tipo de roca, textura (de visu, utilizando una tarjeta de texturas detríticas finas) y posibles variaciones composicionales y texturales (grano selecciones positivas o negativas). La presencia y contenido genérico de carbonatos se determinó de visu mediante la aplicación de ácido clorhídrico diluido (agua fuerte) a lo largo del nivel.

Determinación de la coloración superficial del nivel, tanto en seco (superficie de afloramiento) como en húmedo (tras pulverizarlo con agua fumigada), utilizando una escala Munsell de colores.

Descripción de las estructuras sedimentarias presentes, tanto de corriente (laminaciones, rizaduras, imbricaciones...), biogénicas (bioturbaciones, rizoconcrecciones, etc.) o postsedimentarias (cementaciones, huellas de escape, etc.). Mediciones de direcciones y sentido de las estructuras (empleando una brújula geológica Silva $15 \mathrm{~L}$ ) y sus dimensiones (con flexómetro).

Además, entre 2012 y 2014 se ha llevado a cabo un análisis granulométrico detallado (ocho fracciones con tamices ${ }^{1}$ y sedimentación con Sedigraph), con determinación de contenido en carbonatos (UNE 103200 ) y en materia orgánica (UNE 103204), en ocho muestras de las unidades litológicas C, D, E (2), G, M y $\mathrm{O}(2)$ (ver situación de los muestreos para granulometría en la columna general del yacimiento con los diferentes muestreos (Fig. 7).

\footnotetext{
(1) El análisis granulométrico se realizó con una torre de tamices normalizados entre 8 y $0,0625 \mathrm{~mm}$ de luz de malla, empleando un agitador analógico, con intensidad 9/10 durante 20 minutos; las fracciones se pesaron en una báscula granataria de gramo.
} 
En cuanto al análisis horizontal (b), por superficies de excavación, se ha atendido especialmente a la identificación del buzamiento de los niveles, a los clastos presentes (tamaños y morfologías), así como su disposición preferente; e.g. en la campaña de 2013, se contabilizaron hasta 18.200 clastos, de los cuales 852 eran mayores de $10 \mathrm{~cm}$; esta información nos ha ayudado a completar la descripción de las distintas unidades. En cuanto al material arqueológico, además de topografiar cada pieza con coordenadas UTM, se ha registrado su buzamiento y posición, atendiendo al eje mayor de cada pieza (ósea o lítica), con el objetivo de completar el análisis de los niveles arqueológicos, información que nos facilitará el estudio de los horizontes de actividad humana y la identificación de niveles de ocupación.

En cuanto a la cronología, hasta la fecha, únicamente se han obtenido cuatro dataciones numéricas. Estas dataciones proceden de la aplicación del método OSL -Optical Stimulating Luminiscence- sobre el sedimento, y fueron realizadas en el Nordic Laboratory for Luminiscence Dating, de Ris $\varnothing$ (Dinamarca) entre 2012 y 2014 (Álvarez Alonso et al., 2016). Además, se han tomado otras tres muestras para OSL en el conjunto medio e inferior, así como también tres muestras de hueso de la unidad $D$ y tres muestras de hueso en el nivel 3 (unidades $E+G$ ), para su datación por AMS; todas ellas están siendo procesadas en el laboratorio de geocronología de la Universidad de Colonia (Alemania).

Los resultados que tenemos, a fecha de hoy, proceden del análisis de tres muestras de sedimento, utilizando granos de cuarzo para la medición (132101, $132102,132103)$ para lo cual se ha usado el protocolo SAR (single-aliquot regenerative). Una cuarta muestra, la primera en analizarse, fue datada a partir del feldespato presente en la misma (122108), aplicando en este caso el protocolo IRIR 290 (Álvarez Alonso et al., 2016).

\section{Análisis geoarqueológico del entorno}

El análisis del entorno se ha estructurado en distintas actuaciones independientes pero complementarias entre sí, y a su vez con el estudio del Abrigo del Molino. De este modo, en primer lugar se ha realizado una descripción del medio físico y geológico, atendiendo especialmente a las litologías y procesos geomorfológicos que han modelado el sector del valle analizado. Asimismo, se ha empezado a realizar un análisis espacial mediante la creación de un Sistema de Información Geográfica -SIG-, con el que se pretenden analizar los factores que pudieron condicionar el poblamiento humano durante el Paleolítico, usando un sistema de evaluación multicriterio. Los principales factores analizados son los geodinámicos y los abióticos. Estos últimos juegan, sin duda, un papel primordial, pues condicionan la disponibilidad de refugio, recursos hídricos o materias primas.

Por otra parte, entre 2013 y 2016 se realizó una primera fase de prospecciones sistemáticas en el valle alto del Eresma, en el sector situado entre su confluencia con el río Ciguiñuela y el arroyo de Tejadilla. En el marco de estas prospecciones, se han llevado a cabo distintos sondeos arqueológicos, algunos de los cuales han aportado resultados positivos y relevante información geológica, mediante el levantamiento de columnas estratigráficas. En último lugar, también se llevó a cabo un análisis de captación de materias primas, enfocado únicamente a la descripción litológica de los aluviones del Eresma, mediante la prospección de su cauce alto y sistema de terrazas.

\section{El Abrigo del Molino}

El Abrigo del Molino se sitúa en la margen izquierda del río Eresma, a unos $11 \mathrm{~m}$ sobre su cauce actual aguas abajo de su confluencia con el arroyo Clamores, en el paraje conocido como Molino de los Señores, que da nombre al yacimiento. Este enclave se localiza a las afueras de la ciudad de Segovia, a 1 $\mathrm{km}$ aguas abajo del Alcázar, siguiendo el curso del Eresma (Fig. 3).

Fue descubierto en el mes de abril del año 2012, en el transcurso de un proyecto de investigación iniciado en 2009, y se comenzó a excavar en julio de 2013, tras la realización de una serie de análisis preliminares que sirvieron para contextualizar el hallazgo (Álvarez Alonso et al.,2013a; 2014a) (Fig. 4). Se trata de una cavidad kárstica completamente fosilizada y colmatada hasta el techo por sedimentos exokársticos y endokársticos, que a comienzos de la década de 1980 fue seccionada por las obras de canalización para el soterramiento del colector de aguas residuales de la ciudad de Segovia. Esta circunstancia motivó la desaparición de buena parte del abrigo y su relleno sedimentario, pasando desapercibida la existencia de restos arqueológicos en el lugar, hasta su descubrimiento (Álvarez Alonso et al., 2014a) (Fig. 5).

Desde un punto de vista fisiográfico, el yacimiento se localiza justo en el enlace entre el piedemonte septentrional de los Montes Carpetanos en la Sierra de Guadarrama (Sistema Central español) y el sector centro-meridional de la Submeseta Norte o Cuenca del Duero. Más en concreto, en uno de los cañones y hoces que surcan el piedemonte del Guadarrama, 


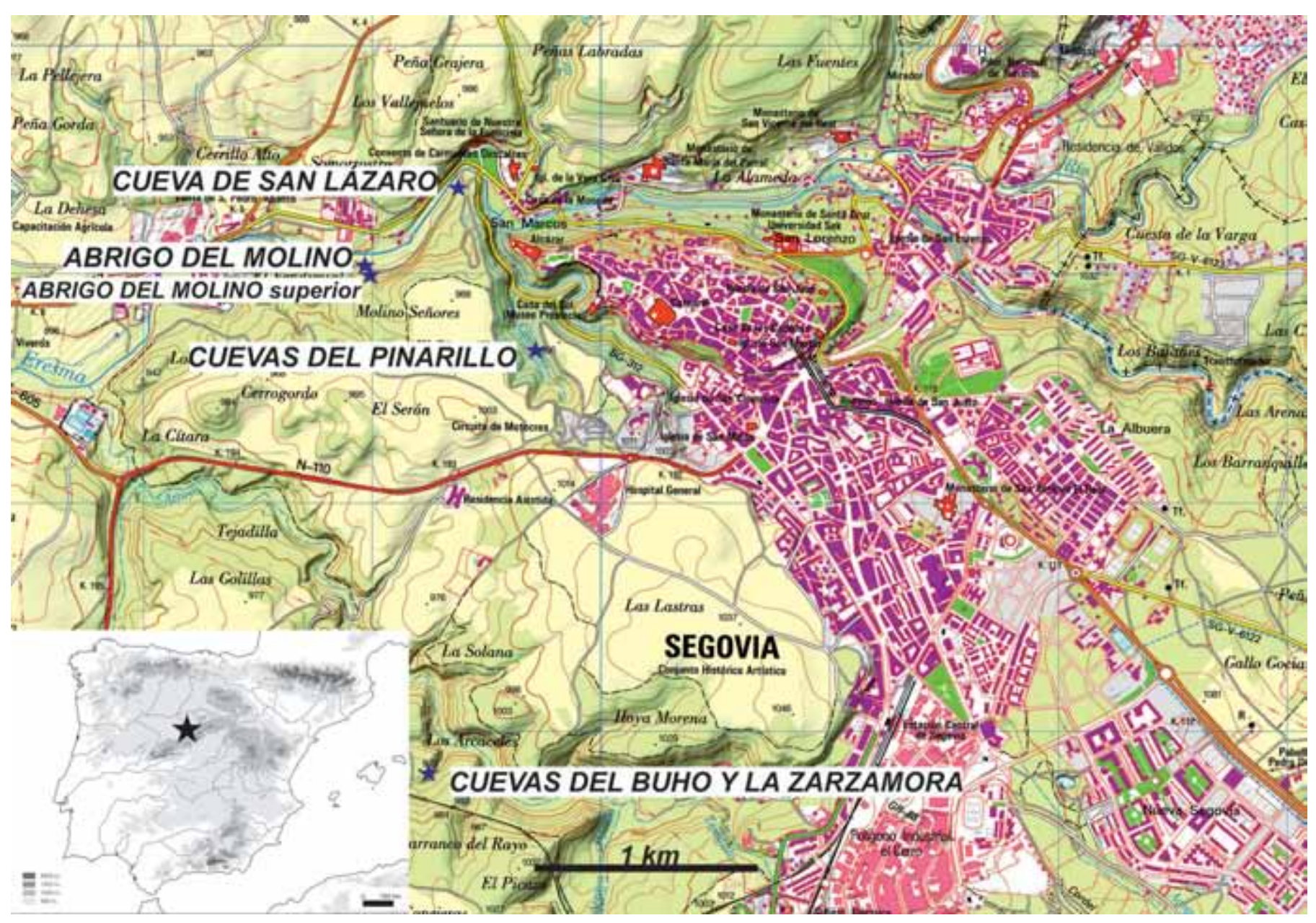

Figura 3. Situación geográfica del Abrigo del Molino y otros yacimientos citados en este texto.

Figure 3. Geographic location of the Abrigo del Molino and other sites mentioned in this text.

entre la rampa de la Sierra y las campiñas y vegas del Duero, formado por el río Eresma. Las coordenadas son: UTM Huso 30, X 403.957, Y 4.534.032.

El Abrigo se formó sobre materiales del Cretácico superior, dentro de la orla de materiales mesozoicos que se ubican discordantes sobre los materiales proterozoicos y paleozoicos del piedemonte de la Sierra de Guadarrama (Zona Centroibérica del Macizo Hespérico varisco), y parcialmente cubierta de forma también discordante por los depósitos cenozoicos de la cuenca sedimentaria del Duero.

En concreto, según la cartografía geológica oficial (MAGNA; Martínez-Salanova et al., 1991) la cavidad donde se sitúa el yacimiento se desarrolló en varios bancos de potencia métrica de dolomías arenosas, dolomías y calizas margosas, del Miembro 'Areniscas y arcillas de Hontoria' de la Formación 'Dolomías tableadas de Caballar', justo en la transición al Mb. 'Areniscas dolomíticas de Hontoria' de la Fm. 'Calizas y dolomías de Castrojimeno'; asignadas ambas al
Coniaciense-Santoniense (Cretácico superior). En la redefinición de unidades realizada por Gil et al. (2010) corresponderían a la transición entre las formaciones 'Ituero y Lama', 'Caballar' y 'Montejo', aquí con edad Santoniense inferior (Fig. 2).

Toda la serie mesozoico-paleógena se encuentra, en las inmediaciones del yacimiento del Abrigo del Molino, afectada tectónicamente por el plegamiento de la cobertera sedimentaria asociada a la orogenia Alpina (fase Guadarrama), que aquí formó un pliegue anticlinal, casi monoclinal (flanco SE, buzamiento $6^{\circ}$ ), asociado a una falla inversa del zócalo cristalino, con el eje de dirección SO-NE, inmersión hacia el SO, y vergencia hacia el NO, cuyo flanco $\mathrm{NO}$ alcanza los $50^{\circ}$ de buzamiento hacia este punto cardinal. En detalle, el yacimiento se encuentra en la transición de la charnela del núcleo aflorante del pliegue hacia el flanco subverticalizado, observándose abundante diaclasado y pequeñas fallas de deslizamiento banco sobre banco, con estrías y escalones de falla en calcita. 


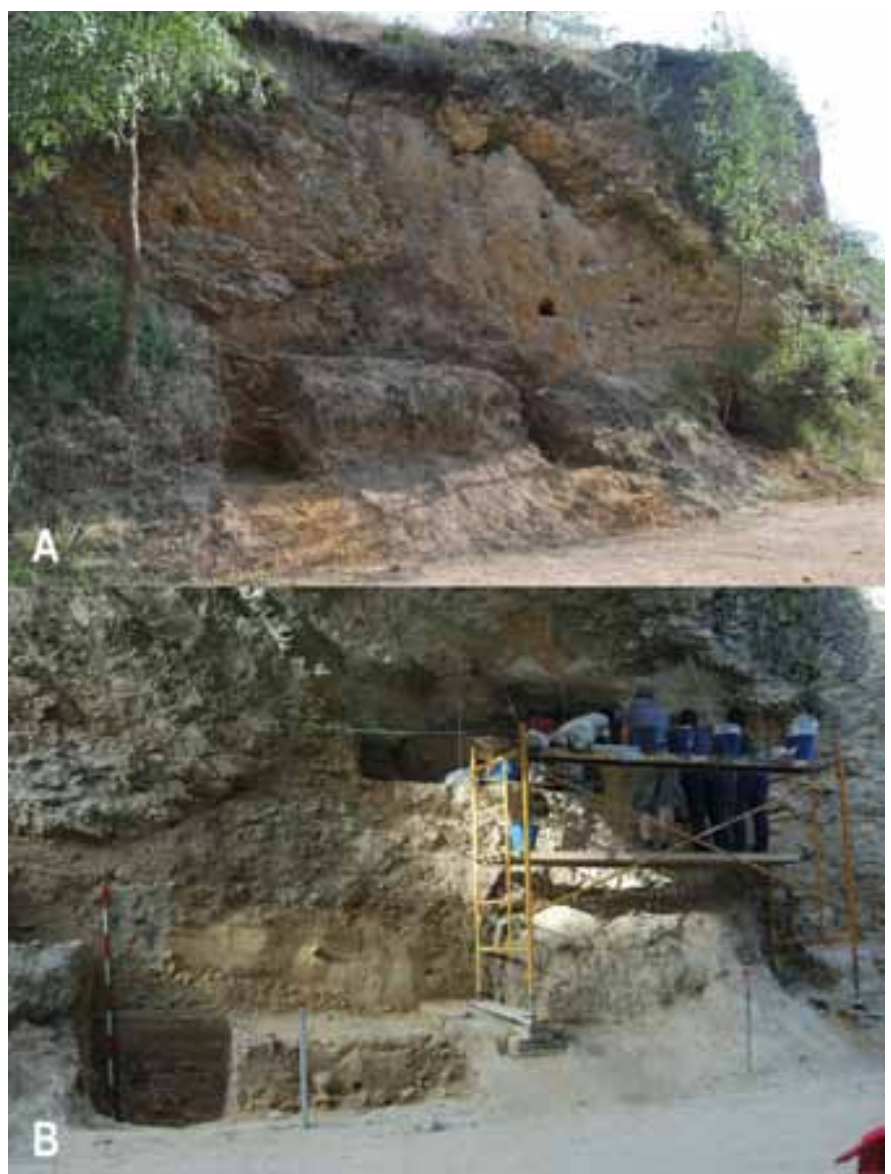

Figura 4. A. Fotografía del yacimiento antes del inicio de la excavación en 2013; B. Fotografía tomada durante la campaña de excavación de 2014.

Figure 4. A: photograph of the site before starting the excavation in 2013; B: photograph taken during the archaeological season in 2014.

La cavidad que acoge el yacimiento es en realidad consecuencia de la karstificación diferencial de los bancos de dolomías arenosas y dolomías que, en la zona de la charnela del pliegue, forman solapos, abrigos y extraplomos, muy condicionados por el buzamiento de la estratificación y el diaclasado tectónico. Por ello, la cavidad solo tiene un limitado desarrollo en fase freática, ya que la fase vadosa se vio inmediatamente colmatada por depósitos detríticos, sin que se observen espeleotemas de dimensiones significativas. Únicamente se observa un mayor desarrollo de galerías de dimensiones decimétricas (gateras) a partir de niveles más karstificables y de confluencia de diaclasado y planos de estratificación (planos de debilidad).

La incisión del río Eresma formando un cañón asimétrico en este tramo, con el yacimiento en la orilla externa de un meandro, ha generado una ladera de fuerte pendiente en esta margen izquierda, con escalones definidos por la diferente resistencia de los bancos de roca a ser erosionados y karstificados, y terrazas rocosas de estabilización del encajamiento; mientras que en la margen derecha se formó una ladera tendida y escalonada, con desarrollo de apenas dos o tres niveles de terrazas aluviales que enlazan con glacis-terraza, limitados a la barra de la orilla interna del meandro. Finalmente, determinados sectores de la margen izquierda están cubiertos y regularizados por depósitos coluvionares (taludes y conos de derrubios) asociados a los procesos periglaciares (gelifracción por ciclos de hielo-deshielo, gelisolifluxión) y procesos gravitacionales (desprendimientos, vuelcos y deslizamientos traslacionales).

\section{Caracterización geoarqueológica}

Tras una campaña de prospección superficial y tres campañas de excavación arqueológica(2), y después de varias columnas parciales en el relleno sedimentario (Álvarez Alonso et al., 2013a y 2014b; Díez Herrero et al., 2014), finalmente se ha sintetizado una secuencia estratigráfica general, que presenta unos $4,5 \mathrm{~m}$ de espesor máximo, y está compuesta por 16 unidades litológicas (etiquetadas con las letras de la $A$ a la $P$, de techo a base respectivamente; Fig. 6 y 7), identificadas a partir del análisis y correlación de nueve columnas estratigráficas realizadas en diferentes sectores del yacimiento, siempre sobre el perfil E-O.

En primer lugar, en lo que se refiere a la composición de las unidades litológicas, todos los materiales presentes en cada una de ellas se corresponden con sedimentos detríticos no cementados y algo consolidados, de diferente granulometría, entre arcillas y limos arcillosos, y gravas, cantos y bloques. En la secuencia general alternan niveles de granulometría predominantemente fina, de arenas, limos y arcillas (A, C, E, G, I, K, M, O) con otros fundamentalmente gruesos, de conglomerados de gravas, cantos y bloques $(B, D, F, H, J, L, N, P)$; si bien no todos ellos tienen continuidad lateral y presencia en todo el yacimiento.

\section{Unidades estratigráficas}

A partir de las nueve columnas estratigráficas-sedimentológicas levantadas entre 2013 y 2014, y de los (2) La información recogida en este artículo solo contiene los
datos de las campañas 2013-2015. 


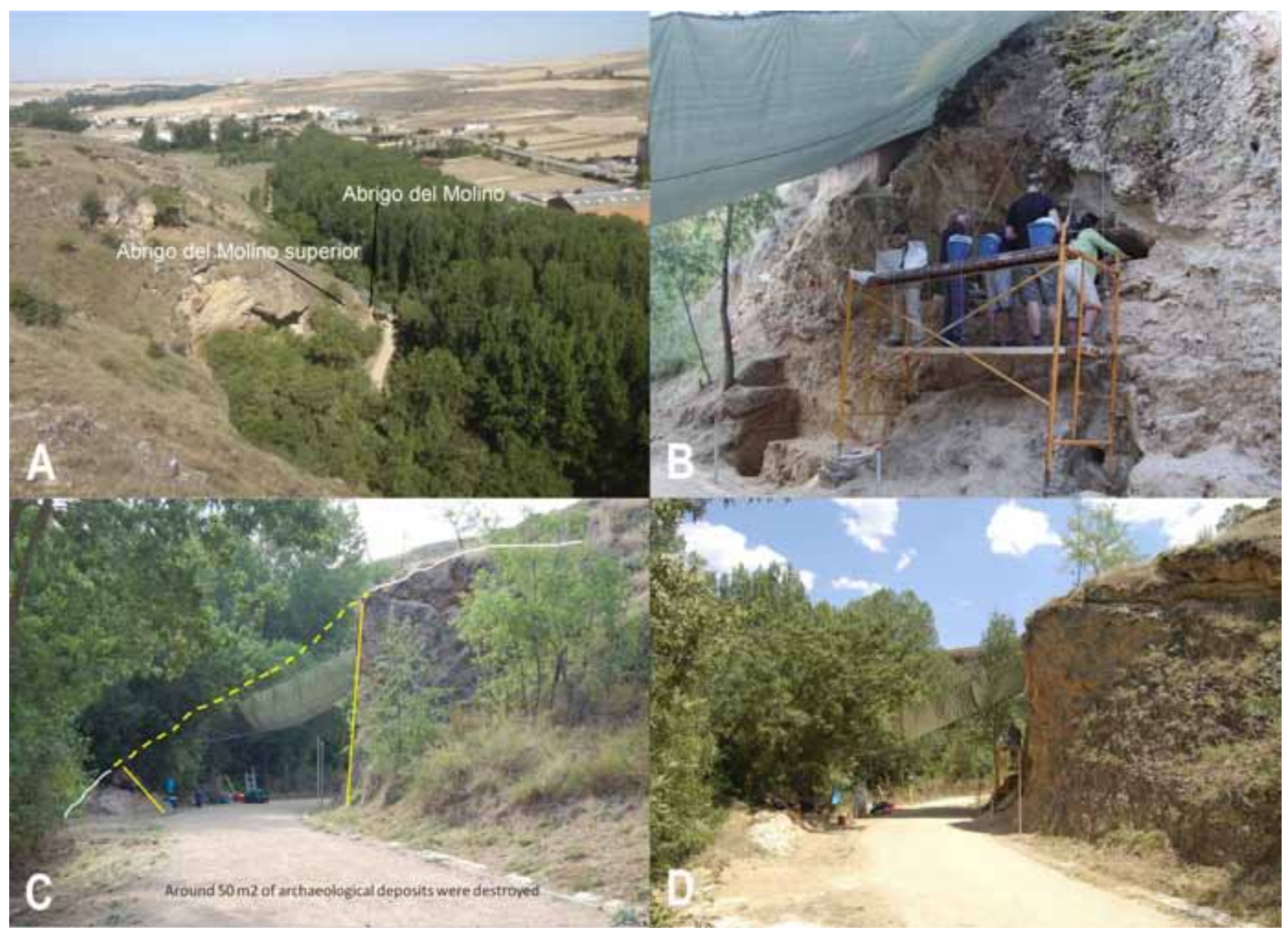

Figura 5. A. Imagen con la ubicación del Abrigo del Molino y la zona superior, en la margen izquierda del río Eresma; B. Fotografía del proceso de excavación en 2014; C. Vista del yacimiento desde el O. El color amarillo indica la parte del yacimiento que fue destruida; D. Vista del yacimiento desde el $\mathrm{O}$.

Figure 5. A: photograph with the location of the Abrigo del Molino on the left bank of the Eresma River; B: photograph of the excavation process in 2014; C: view of the site from the W. Yellow colour represents the part of the site that was destroyed; D: view of the site from W.

paneles de correlación entre ellas, se han podido diferenciar las siguientes unidades (denominadas con letras mayúsculas) de acuerdo a sus características y diferencias litológicas (ver espesores y más detalles en la columna de síntesis de la figura 7; y sus relaciones geométricas laterales en la estratigrafía de la figura 8). De techo a muro (base), se puede diferenciar:

A) Rango de espesores: 0,2 a 1,1 m. Limos arcillosos con gravas y cantos calcáreos dispersos que van de tamaño milimétrico a centimétrico, con una dimensión máxima de $5 \mathrm{~cm}$ y algún bloque suelto, sin ningún tipo de orientación. En la parte superior está cementado por carbonatos y tiene coloraciones más blanquecinas; colores Munsell Soil-Color Charts, 10YR 8/2 en seco y 10YR 6/6 en húmedo. A techo, el contac- to con el muro superior del abrigo es irregular y se acuña hacia el O. Existen pequeños rizotúbulos de tamaño milimétrico y restos de microfauna en la base del nivel.

B) Rango de espesores: 0,16 a 0,6 m. Conglomerado de cantos y bloques de rocas carbonáticas angulosas con dimensiones en torno a los $5 \mathrm{~cm}$. Hacia la parte central del corte los clastos son más grandes y planares, todos ellos en posición subhorizontal. El nivel se acuña hacia el O. Se localizan restos de microfauna.

C) Rango de espesores: 0,1 a 0,4 m. Limos arenosos, de color pardo rojizo claro en seco y marrón claro (camel) en húmedo, con bloques y gravas intercalados, y presencia de carbona- 


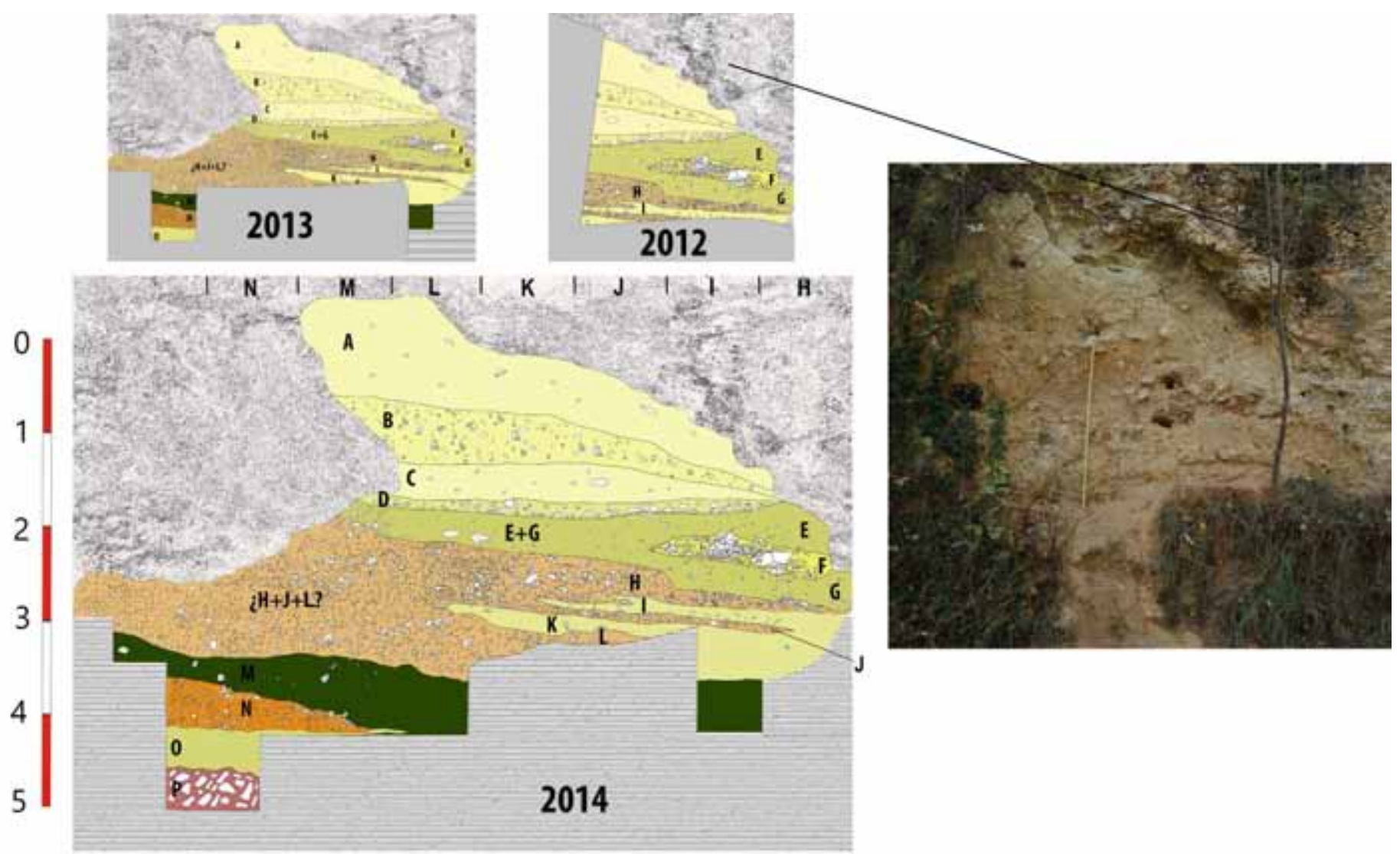

Figura 6. Evolución del perfil estratigráfico visible, desde 2012 a 2014.

Figure 6. Evolution of the visible stratigraphic profile, from 2012 to 2014.

tos a lo largo del nivel. Se registran clastos de caliza soportados por la matriz, con gravas intercaladas, dispuestas caóticamente; hay rizoconcrecciones dispersas por todo el nivel, cortas $(1-2 \mathrm{~cm})$ y muy finas; y restos de Industria lítica, macrofauna y microfauna. En la parte superior del nivel hay una mayor concentración de gravas que en la inferior, en la que aparecen más dispersas.

D) Rango de espesores: 0,1 a 0,3 m. Conglomerado de bloques dispersos en matriz limo-arenosa. Bloques soportados por la matriz, de formas irregulares y angulosas, la mayor parte planares que se disponen en dos horizontes. Matriz con gravas intercaladas. Color seco, beige-pardo claro; color húmedo, pardo-rojizo claro. Límite inferior difuso e irregular; límite superior difuso e irregular. Rizoconcrecciones oblicuas de longitud máxima de $4 \mathrm{~cm}$ y grosor 1-2 $\mathrm{mm}$. Presencia de restos líticos y de fauna.

E) Rango de espesores: 0,2 a 0,3 m. Limos areno- sos con clastos de caliza que oscilan desde los 10 a $5 \mathrm{~cm}$, con formas irregulares planares pero también redondeadas. Nivel de carbonatos en los limos, uniforme en todo el nivel. Rizoconcrecciones de hasta $8-9 \mathrm{~cm}$ y un milímetro de diámetro; el diámetro de algunas aumenta hasta los $4 \mathrm{~mm}$; solo aparecen en la parte superior del nivel; disposición oblicua. Color tostado-rojizo en seco; en la parte superior es más claro por la cementación de carbonatos. Límite inferior muy irregular; lateralmente se une al nivel $G$ hacia el Este, por acuñamiento del nivel $F$. Presenta restos de industria lítica y fauna.

F) Rango de espesores: 0,0 a 0,2 m. Conglomerado de cantos y bloques con matriz arcillo-arenosa y de gravas. Los bloques miden desde $55 \mathrm{~cm}$ hasta $8 \mathrm{~cm}$; son de formas irregulares y angulosas pero planares. Hay zonas donde están soportados por la matriz y otras en las que aparecen soportados por los clastos. Clastos de calizas y matriz de carbonatos. Color 


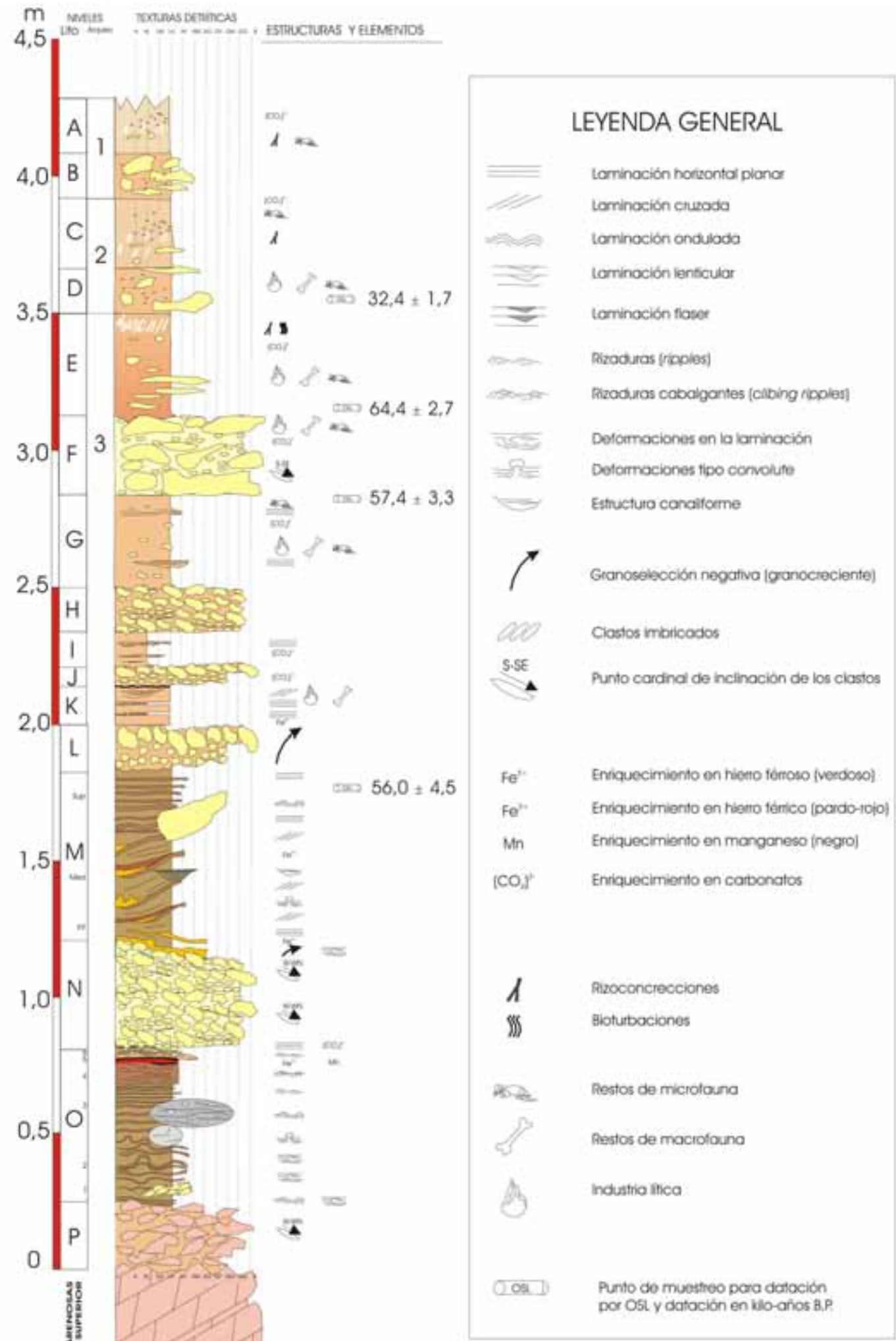

Figura 7. Columna estratigráfica general del Abrigo del Molino. Figure 7. General stratigraphic profile of the Abrigo del Molino. 
pardo-rojizo claro en seco y amarillento rojizo en húmedo. Contacto inferior neto y plano; contacto superior neto pero muy irregular. Presenta restos de fauna e industria lítica.

G) Rango de espesores: 0,1 a 0,4 m. Limos arenosos con cantos dispersos desde 1 a $3 \mathrm{~cm}$. Color beige tostado algo más amarillento en seco (10YR 7/4) y más rojizo en húmedo (5YR 5/6). Tienen contenido en carbonatos todos los limos del nivel. Los clastos son de formas irregulares pero con las aristas redondeadas. En general es masivo pero hay niveles con laminación horizontal que coinciden con los niveles más arenosos. Contacto inferior neto pero irregular; contacto superior neto y bastante planar, aunque con alguna irregularidad. Presenta abundante industria lítica y fauna.

$\mathrm{H})$ Rango de espesores: 0,1 a 1,6 $\mathrm{m}(\mathrm{H}+\mathrm{J}+\mathrm{L})$. Conglomerado de gravas y cantos en matriz limosa de color beige tostado en seco y marrón claro en húmedo. Se identifican de visu, sin análisis clastométricos cuantitativos, dos modas no muy definidas de clastos de entre $3 y$ $4 \mathrm{~cm}$, y de más de $8 \mathrm{~cm}$. Los clastos son mayoritariamente de caliza y tienen morfologías irregulares, pero ligeramente redondeadas. Los clastos están soportados por la matriz. La disposición en algunas zonas es ordenada, pero en otras es anárquica. El contacto inferior es neto pero alabeado, y el superior es neto pero irregular.

I) Rango de espesores: 0,0 a 0,3 m. Limos arcillosos de color beige tostado en seco y de color marrón claro en húmedo. El contacto con el nivel superior es neto, ligeramente alabeado. El contacto inferior es neto pero muy irregular, mezclándose con el nivel inferior. En conjunto es masivo, pero se observan algunas láminas subhorizontales con granulometrías un poco más gruesas.

J) Rango de espesores: 0,0 a 1,6 m $(H+J+L)$. Conglomerado de gravas y cantos en algunos sitios soportado por los clastos y en otros por la matriz, con algunos cantos de $5 \mathrm{~cm}$ dispersos, con matriz de limo arenoso con carbonatos y clastos de caliza. Color beige-tostado amarillento en seco. Límites: superior, neto pero irregular; inferior, neto pero bastante plano.

K) Rango de espesores: 0,0 a 0,3 m. Limos arenosos de color beige pardo claro. El contacto superior es neto pero irregular. Dentro del nivel se pueden diferenciar al menos dos subniveles: en el superior hay un predominio de limos arenosos con pequeñas laminaciones onduladas; en el inferior hay bandas de $1 \mathrm{~cm}$ ligeramente onduladas de limos arcillosos, donde existen unos pocos clastos de $1 \mathrm{~cm}$ dispersos. No se observan rizoconcrecciones. En la parte inferior hay unas láminas ligeramente verdosas por óxidos de hierro ferrosos. Contiene restos de industria lítica y de fauna.

L) Rango de espesores: 0,0 a 1,6 m (H+J+L). Limos arenosos con laminaciones difusas y color pardo oscuro. Los contactos con los niveles superior e inferior son graduales e imperceptibles. Tiene dispersos clastos de caliza de hasta $6 \mathrm{~cm}$ soportados por la matriz, dispuestos caóticamente. Contiene carbonatos a lo largo de todo el nivel.

M) Rango de espesores: 0,3 a 0,6 m. Limos arenosos de color pardo, de pardo oscuro en la parte superior a pardo más claro en la parte inferior. El nivel tiene una tenue granoselección positiva (hacia arriba tiene la matriz más arcillosa, en los $14 \mathrm{~cm}$ superiores). En la parte media, entre los 36 y los $50 \mathrm{~cm}$ presenta unas laminaciones subhorizontales muy marcadas de alternancia de limos arenosos y pasadas con mayor contenido de arcilla, de color más claro las de mayor contenido en arcilla. En la parte inferior del perfil hay una lámina con difusión de óxidos de hierro y de manganeso formando círculos de Liesegang.

N) Rango de espesores: 0,1 a $0,5 \mathrm{~m}$. Conglomerado de gravas medias y gruesas de cantos angulosos irregulares de carbonatos, soportados por los clastos, con matriz arenosa gruesa. Color beige para el conjunto del nivel. Límite superior irregular, marcado por la forma de los clastos, pero neto y brusco. Ligera orientación del eje largo de los clastos alargados hacia el O-ON, como pendiente deposicional con el nivel $\mathrm{M}\left(16^{\circ}\right)$.

O) Rango de espesores: 0,3 a 0,4 m. Arenas finas, muy finas y limos con diferentes subniveles y alternancias, con marcadas laminaciones subhorizontales, onduladas y rizaduras (ripples cabalgantes o trepadores; climbing ripples), en muchos lugares deformadas. Intercalados hay niveles de cantos angulosos de dolomías en la parte inferior, y cantos rodados decimétricos aislados de naturaleza cristalina (gneises y granitoides) en la parte media-baja del nivel.

P) Rango de espesores: 0,2 a 0,3 m. Conglomerado de bloques y cantos angulosos (brecha) de dolomía arenosa rosácea, soportado por los clastos y con matriz arenosa. Límite inferior con la roca de caja, las areniscas dolo- 


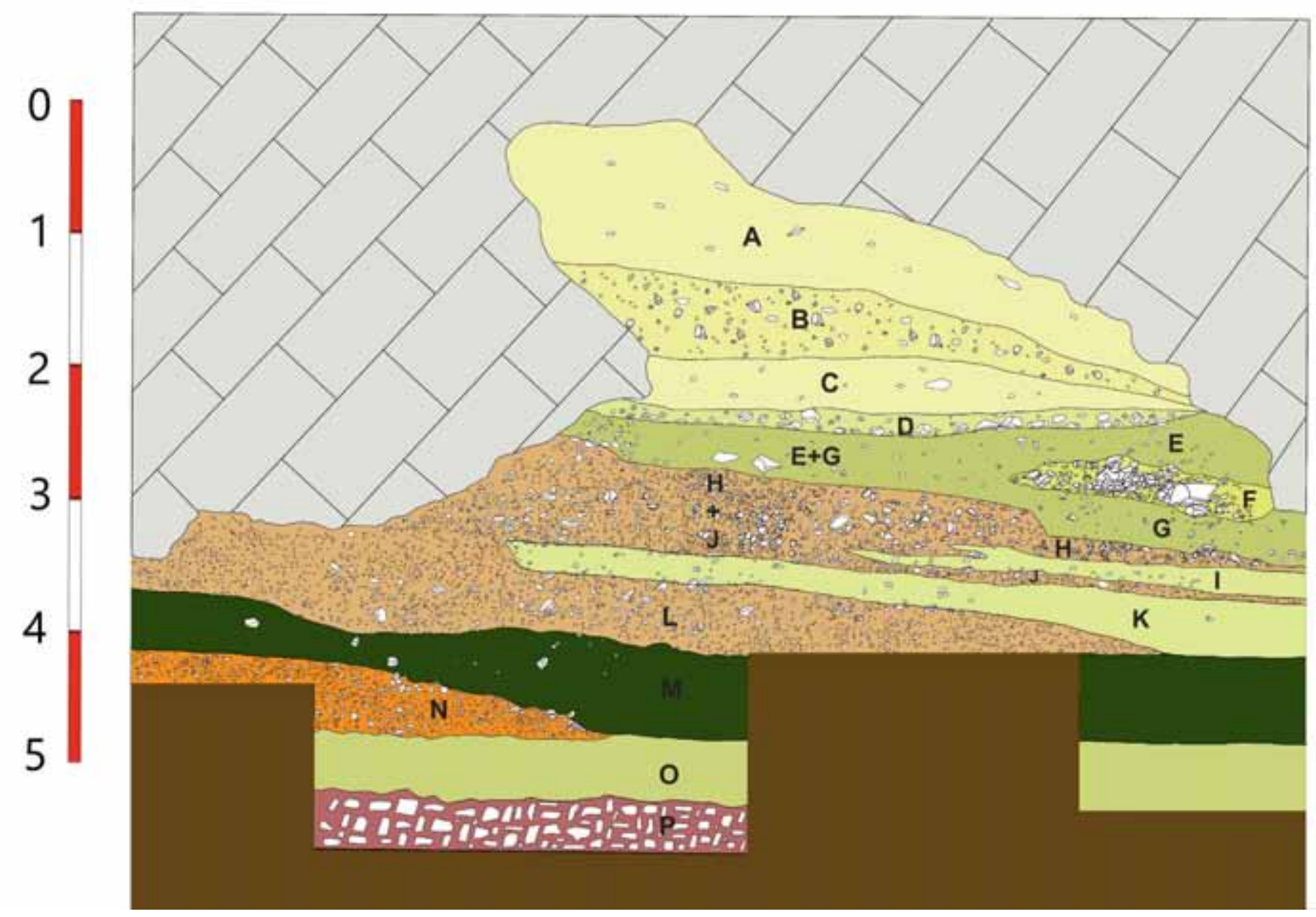

Figura 8. Perfil estratigráfico, E-O en 2015.

Figure 8. Stratigraphic profile, E-W in 2015.

míticas cretácicas, es irregular pero neto; límite superior irregular y muy neto; no se aprecia gradación.

\section{Interpretación de la génesis del depósito}

Como resultado del estudio geométrico de los niveles, su disposición espacial, y de sus estructuras sedimentarias y otros elementos presentes, se han podido diferenciar tres conjuntos litológicos asociados a otras tantas secuencias de procesos genéticos, en los que se engloban las diferentes unidades identificadas: Conjunto inferior, intermedio y superior (Díez Herrero et al., 2014).

Conjunto inferior, compuesto por los niveles $\mathrm{P}$ a $M$, y que corresponden a la alternancia de depósitos coluvionares de pie de talud de derrubios (gravas y cantos soportados por los clastos, con orientaciones según pendiente deposicional) y depósitos de remanso en barra de remolino durante paleoinundaciones (limos y arenas muy finas con secuencias de rizaduras trepadoras o climbing ripples (Díez Herrero et al., 2014); todos ellos alóctonos al sistema kárstico.

Conjunto intermedio, compuesto por los niveles $\mathrm{L}$ a $\mathrm{H}$, y que corresponde a la alternancia de depósitos coluvionares de pie de talud de derrubios (gravas grano y matriz-sostenidos con secuencias granocrecientes) y depósitos de coladas de barro (limos y arenas limosas con laminación puntual); intercalando materiales alóctonos y autóctonos al sistema kárstico.

Conjunto superior, compuesto por los niveles $\mathrm{G}$ a $A, y$ que corresponde a la alternancia e interdigitación de niveles de desprendimientos de techo de la cavidad por gelifracción y termoclastia (cantos y bloques irregulares soportados por los clastos) y depósitos de coladas de barro y niveles de meteorización físicoquímica (carbohidrólisis) de la roca de caja por areni- 
zación (limos y arenas cementados por carbonatos); todos ellos autóctonos (endokársticos), pero lo suficientemente próximos a la entrada de la cavidad, para que pueda haber fenómenos periglaciares.

Para referirnos a las unidades litológicas identificadas en la secuencia estratigráfica se han utilizado letras ( $A$ a $P$ ) mientras que, por otra parte se han empleado números para denominar los niveles arqueológicos ( 1 a 3 hasta el momento), que en alguna ocasión engloban más de una unidad litológica (Fig. 7). Esto se debe, fundamentalmente, a la existencia de fenómenos puntuales como la gelifracción, que generan depósitos que no tienen continuidad lateral por toda la superficie de la cavidad -como así sucede por ejemplo con la unidad F-, o unidades que parecen formar parte de un mismo fenómeno y solo son perceptibles en una parte de la secuencia, como así sucede con las unidades $E$ y $G$, o con las unidades H, J y L (Fig. 7 y Fig. 8).

Hasta la campaña de 2015, objeto de este estudio, solo se alcanzó la unidad G; siendo la correlación entre unidades litológicas y niveles arqueológicos la siguiente:

- Nivel 1 (unidades A y B): estéril desde un punto de vista arqueológico, solo hay presencia de algunos restos de microfauna que desaparecen a techo en la unidad $A$.

- Nivel 2 (unidades C y D) contiene industria lítica, macrofauna y microfauna, sobre todo en la base del nivel (unidad D), correspondiente con el final del Musteriense. Las unidades $C$ y $D$ han sido englobadas en un mismo nivel, al no apreciarse diferencias significativas, salvo la presencia de un horizonte de bloques y clastos en la base del nivel 2 (unidad D) que apoya directamente sobre el nivel 3 (techo de la unidad E). El contenido arqueológico es coherente a lo largo de todo el nivel, apareciendo todos los restos preferentemente en posición horizontal o subhorizontal, de acuerdo al buzamiento general de cada unidad.

- Nivel 3 (unidades E, F y G) contiene industria lítica, macrofauna y microfauna, habiendo más densidad en la base del nivel (3-G), donde se ha identificado un suelo de ocupación musteriense. Las unidades $E$ y $G$ parecen ser el mismo horizonte, que en la zona $\mathrm{O}$ del abrigo se engro$\mathrm{sa}$, al tener intercalada una cuña de clastos desprendidos del techo (unidad F) que se encuentra muy bien delimitada en ese sector del relleno sedimentario (Fig. 8), y se vincula a un fenómeno de gelifracción inmediatamente posterior al nivel de ocupación identificado en la base del nivel 3 .
Además de estos niveles que han sido ya excavados, se han documentado piezas de sílex y fragmentos de fauna con marcas antrópicas en la unidad litológica $K$, que aún no ha sido excavada. La unidad $K$ es el primer horizonte con ocupación humana en la secuencia del abrigo ya que, hasta la fecha, el conjunto inferior (P-M) se ha mostrado completamente estéril.

Por otra parte, la interpretación genética para los tres conjuntos y los diferentes niveles, permite reconstruir la evolución temporal de los procesos que han dado lugar al relleno sedimentario, en una secuencia de 15 etapas que se esquematiza simplificadamente en la (Fig. 9). La génesis del relleno sedimentario de la cavidad se ha producido atendiendo a tres principales agentes formadores o morfogenéticos: a) fluvial, formando niveles de depósitos de paleoinundación (palaeofloods), situados en la base de la secuencia; b) gravitacional, dando lugar a coluviones aportados desde las laderas del exterior de la cavidad; c) kárstico, origen asociado al relleno detrítico de una cavidad con materiales procedentes del propio sistema de cavidades. Tanto el aporte de sedimentos de paleoinundación como de materiales provenientes de la ladera, son fenómenos que actúan relativamente rápido y de manera más esporádica; ambos afectan, sobre todo, a la parte inferior y media del depósito sedimentario. Por otra parte, la formación de sedimentos detríticos por disolución, colapso y descomposición de la roca, es un proceso mucho más continuo y prolongado en el tiempo, que afecta a toda la secuencia, pero que una vez que el río está más encajado y la ladera más estabilizada, solo afecta ya a la parte superior del relleno. Estos fenómenos de meteorización físico-química de la roca encajante han sido el único agente formador del depósito en su última etapa, hasta llegar a la fosilización completa, mediante procesos de carbonatación, que afectan sobre todo el conjunto superior, de manera especial a las unidades $\mathrm{A}$ y $\mathrm{B}$.

\section{Análisis cronométrico de la secuencia}

En primer lugar hay que mencionar que en 2013 se publicó la primera datación (122108), tomada en 2012 antes de iniciarse las excavaciones, en la base de la unidad litológica $\mathrm{E}$-justo en el contacto con F- (Álvarez Alonso et al., 2013a). Esta datación arrojó una edad de $59700 \pm 2700 \mathrm{BP}$, que posteriormente ha sido corregida, hasta obtener un valor final de $64400 \pm 2700 \mathrm{BP}$ Tras un exhaustivo análisis de la secuencia de dataciones obtenida en Ris $\varnothing$ (Álvarez Alonso et al., 2016), consideramos que la datación 122108 está considera- 

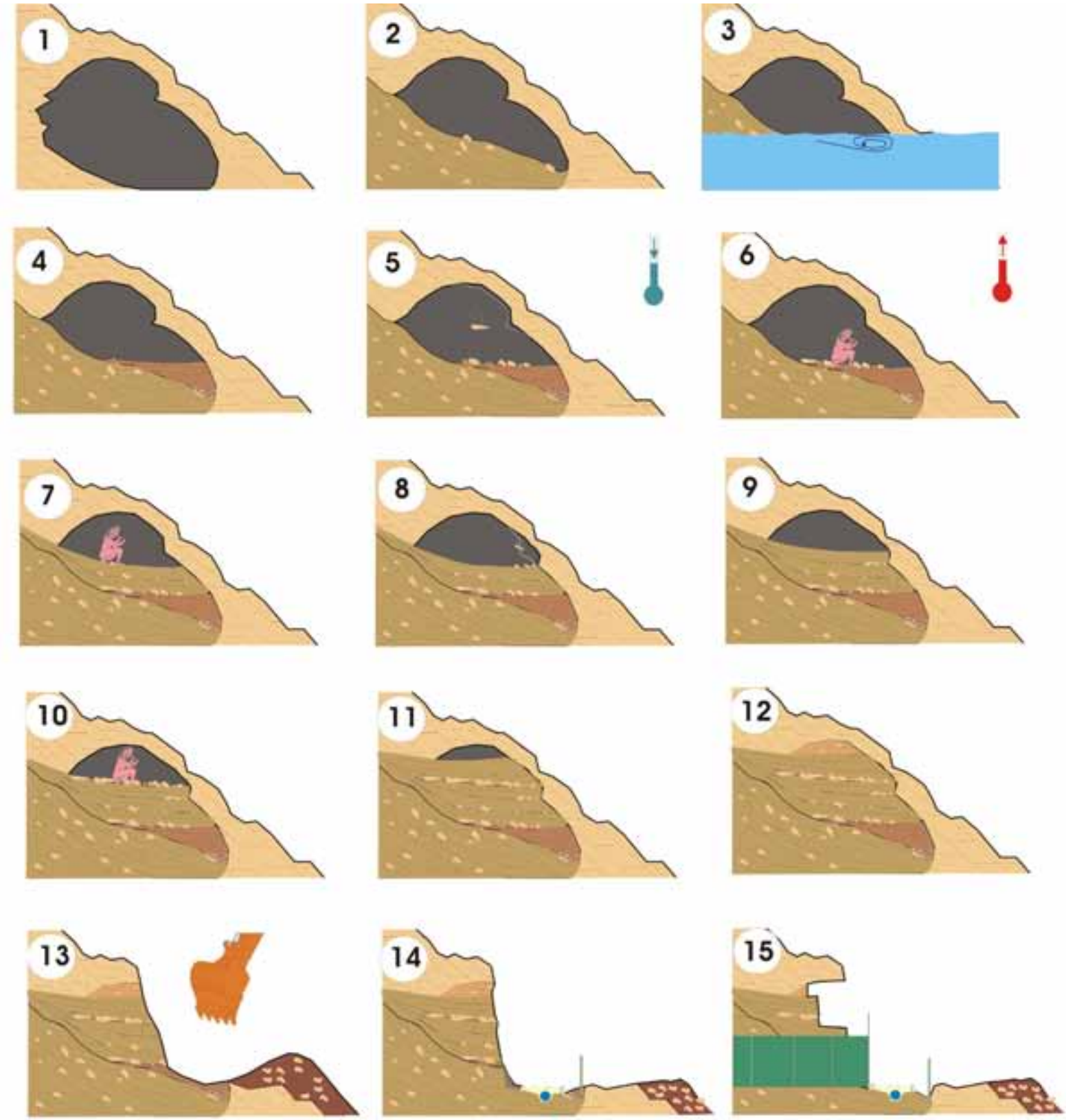

Figura 9. Secuencia evolutiva de la interpretación geoarqueológica de la génesis del Abrigo del Molino (vista lateral desde el E-NE): 1. Formación de la cavidad fluvio-kárstic en el flanco de un pliegue monoclinal; 2. Parte rellenada en la base de la cavidad por depósitos coluviales de ladera; 3 . Eventos de paleoinundación que forman barras de remolino sobre la roca basal, y depositan niveles de arenas y limos (4); 5 . Caída de clastos del techo a causa de procesos de hielo-deshielo; 6 . Primer nivel con restos de ocupación humana; 7. Depósito de ladera y coladas de barro del sistema kárstico, con restos de ocupación humana; 8 . Caída de clastos del techo a causa de procesos de hielo-deshielo que afectan solo al sector 0; 9. Nuevos depósitos de ladera y coladas de barro; 10. Caida de bloques y ocupación humana intensiva; 11. Nuevo relleno de depósitos de ladera y coladas de barro; 12. Relleno final y erosión de la superficie de la roca; 13. Apertura de una trinchera a principios de los años 80 , que destruyó una gran parte del yacimiento; 14 . Estado del yacimiento en el momento del descubrimiento en 2012, con el colector de aguas residuales y el camino natural del río Eresma; 15 . Situación al final de la segunda campaña de excavación, con la verja perimetral.

Figure 9. Evolved sequence of the geoarchaeological interpretation for the genesis of the Abrigo del Molino (lateral view from E-NE): 1. Formation of the fluvio-karstic cavity on the flank of a monoclinal fold; 2 . Part filled in the base of the cavity by colluvial slope deposits; 3. Palaeo-flood events which formed an eddy bar over the bed rock and deposited layers of sand and silt (4); 5. Roof rock falls caused by icewedge processes; 6 . First human occupation level; 7 . New fill of slope materials and karstic system mud flows, with human occupation; 8. Roof rock falls caused by ice-wedge processes, affecting W sector; 9 . New slope fills and mud flows; 10 . Boulder falls and intensive human occupation; 11. New fill of slope materials and mud flows; 12. Final fill by weathering of the rock cover; 13. Opening of the trench in the early 1980s, which destroyed a large area of the site; 14. State of site at the time of discovery in 2012, with the wastewater pipe and the trekking trail of the Eresma River; 15. Situation at the end of the second archaeological season, with the perimeter fence. 
blemente envejecida y por lo tanto debemos primar los resultados obtenidos sobre cuarzo, por dos razones fundamentales: el empleo del feldespato en este tipo de analíticas es menos fiable que el cuarzo, aunque permite alcanzar cronologías más antiguas; posteriormente se realizaron tres dataciones sobre cuarzo que han aportado resultados más precisos, sin llegar a saturarse, por lo que todo indica que el resultado de la muestra de feldespato envejece artificialmente el contexto. La comparación entre los resultados aplicando el análisis sobre cuarzo y sobre feldespato, nos ha servido para considerar la muestra 122108, únicamente con el valor de una datación máxima o tope para el contexto arqueológico del Abrigo del Molino, pero no como una datación precisa para contextualizar el nivel del que procede (Álvarez Alonso et al., 2016).

Así, se muestrearon otras unidades que han aportado los siguientes resultados:

La muestra 132101 se corresponde con la unidad G (cuadro l-10), $57400 \pm 3300$

La muestra 132102 se corresponde con la unidad $\mathrm{M}$ (cuadro I-10), $56000 \pm 4500$

La muestra 132103 se corresponde con la unidad D (cuadro K-11), $32400 \pm 1700$

Es preciso remarcar que, desde un punto de vista arqueológico, estos resultados no están datando directamente el contexto de ocupación, como sí podría suceder con las dataciones de radiocarbono sobre materia orgánica (e. g. huesos con marcas antrópicas). En el caso de la OSL se trata siempre de dataciones post quem, que están datando el sedimento en el que está contenido, y que recubre el contexto arqueológico. Para que las evidencias de actividad humana sean sepultadas por sedimentos, dentro de un ambiente endokárstico, ha debido transcurrir un lapso de tiempo indeterminado e impreciso entre el abandono de la ocupación y su recubrimiento completo por parte de sedimentos, hasta formar un horizonte litoestratigráfico definido en el cual muestrear.
Así, la muestra de OSL puede, únicamente, aportarnos una datación para el momento final en el que el nivel arqueológico fue totalmente cubierto por sedimentos, atendiendo a los principios del método de luminiscencia.

Como se ha detallado en el apartado anterior, los procesos genéticos que han tenido lugar en el Abrigo del Molino han actuado con ritmos muy diferentes. Aunque somos incapaces de evaluar realmente el tiempo empleado en cada uno de estos procesos genéticos, ni mucho menos valorar una tasa de sedimentación para cada uno de ellos, sí consideramos que los niveles del conjunto inferior (palaeofloods) tienen una tasa de sedimentación más rápida que el conjunto medio. A su vez, el conjunto superior es el que probablemente se haya formado en un plazo de tiempo más amplio, más lentamente, ya que en este caso únicamente concurrieron procesos endokársticos. Esto podría explicar las diferencias existentes en el cálculo de la dosis anual de la muestra 132103, con respecto a las muestras 132101 y 132102 , como se puede observar en la Tabla 1 (Álvarez Alonso et al., 2016).

Por esta razón, podríamos suponer que el ritmo de formación del relleno sedimentario podría ser cada vez más lento a medida que nos acercamos al techo del abrigo. La hipótesis sería la siguiente: cuanto más arriba de la secuencia nos encontramos, más se amplía el lapso temporal, ya que los procesos sedimentarios del conjunto inferior son rápidos, los del conjunto medio son rápidos, medios y lentos, y los del conjunto superior habrían sido más lentos. Contando con este planteamiento teórico, el primer paso es aportar una edad máxima y una edad mínima para el relleno sedimentario con contenido arqueológico, a partir de los datos obtenidos por la OSL.

Así, como ya hemos indicado, la edad máxima la aportaría la datación realizada en feldespato (122108), considerada la fecha más allá de la cual no podemos hablar de ocupación humana en el Abrigo del Molino,

\begin{tabular}{|c|c|c|c|c|ccc|cc|c|c|}
\hline Sample & Level & Unit lit. & $\begin{array}{c}\text { Heigth } \\
(\mathbf{m})\end{array}$ & w (\%) & \multicolumn{2}{|c|}{$\begin{array}{c}\text { Dose rate } \\
\text { (Gy/ka) }\end{array}$} & \multicolumn{2}{|c|}{$\begin{array}{c}\text { Equivalent dose } \\
\text { (Gy) }\end{array}$} & Age (ka) \\
\hline $\mathbf{1 3 2 1 0 3}(\mathbf{Q z})$ & 2 & $\mathrm{D}$ & 918,842 & 15 & 4.8 & \pm & 0.2 & 154.9 & \pm & 3.3 & $\mathbf{3 2 . 4} \pm \mathbf{1 . 7}$ \\
\hline $\mathbf{1 2 2 1 0 8}(\mathrm{Fd})$ & 3 & $\mathrm{E}$ & 918,587 & 15 & 3.8 & \pm & 0.1 & 246.2 & \pm & 2.0 & $\mathbf{6 4 . 4} \pm 2.7$ \\
\hline $\mathbf{1 3 2 1 0 1}(\mathrm{Qz})$ & 3 & $\mathrm{G}$ & 918,177 & 15 & 3.0 & \pm & 0.1 & 171.2 & \pm & 5.9 & $\mathbf{5 7 . 4} \pm 3.3$ \\
\hline $\mathbf{1 3 2 1 0 2}(\mathbf{Q z})$ & - & $\mathrm{M}$ & 916,833 & 15 & 2.9 & \pm & 0.1 & 164.4 & \pm & 10.8 & $\mathbf{5 6 . 0} \pm \mathbf{4 . 5}$ \\
\hline
\end{tabular}

Tabla 1. Dataciones de OSL.

Table 1. OSL datings. 
Álvarez-Alonso, D., et al., 2018. Análisis geoarqueológico de las ocupaciones... Boletín Geológico y Minero, 129 (1/2): 153-182

al menos en este momento y con los datos de que disponemos. Esta fecha máxima se situaría en la horquiIla 67100-61700 años BP. En segundo lugar tenemos una datación mínima, que nos la aporta la unidad $D$, perteneciente al nivel 2, último horizonte con restos de actividad humana. Esta datación (132103) nos ofrece una horquilla de 34100-30700 años BP, que nos indica que los restos arqueológicos de dicho nivel son necesariamente anteriores a dicho contexto cronológico.

Precisando aún más en la secuencia, y teniendo en cuenta que la única aportación de la datación 122108 es la de ser tenida en cuenta como un valor máximo, debemos fijarnos en la muestra 132102, tomada en el techo del conjunto estratigráfico inferior, concretamente en la unidad $M$, que se corresponde con sedimentos aportados por un evento de paleoinundación. Esta datación, según se deriva de su análisis (Álvarez Alonso et al., 2016), nos ha mostrado un blanqueamiento insuficiente de la señal lumínica de los granos de cuarzo, derivado del origen fluvial de este sedimento. El blanqueamiento insuficiente de una muestra provoca una sobreestimación de la edad, por lo que el resultado de esta datación, podría resultar ligeramente más alto de la edad real, al ampliarse la horquilla -recordamos que la dosis equivalente de esta muestra a partir de la Central Age Model (CAM) es de $164.4 \pm 10.8$, presentando el margen más amplio de los obtenidos (Tabla 1). En consecuencia, esta datación ha arrojado una horquilla situada entre 60500 y 51500 años $\mathrm{BP}$, que nos indicaría que el primer nivel con restos arqueológicos (unidad K), que se sitúa ya en el conjunto intermedio, debe ser, como mucho, contemporáneo o seguramente más reciente de $60 \mathrm{ka}$, la fecha máxima de la unidad $M$.

Por otra parte, la datación 132101 tomada en la unidad G, nos ha aportado una horquilla cronológica situada entre 59700 y 54100 , que se solapa con la datación 132102. Estos resultados no solo nos sirven para aportar una fecha para la unidad G, sino también para considerar que la unidad $\mathrm{K}$ (situada entre $\mathrm{M}$ y $\mathrm{G}$ ), poseería similar rango cronológico, ya que se sitúa necesariamente en una fecha posterior a $60 \mathrm{Ka}$. Estos dos resultados (132101 y 132102) nos confirmarían, además, la invalidez de la datación 122108 obtenida en la unidad E para aportar una cronología a dicho nivel, lo cual se explica por la sobreestimación que implica el uso del feldespato.

Finalmente, con respecto al nivel 2-D, consideramos que su cronología más fiable no es la situada en torno a $32 \mathrm{ka}$, sino la que se ubica en el amplio marco cronológico que se abre entre 54 ka (fecha aportada por la unidad G) y 34 ka (fecha máxima de la unidad D), ya que si entendemos que estos resultados son post quem, se trata de los únicos datos fiables para enmarcar por el momento las últimas evidencias de actividad humana en el Abrigo del Molino, representadas por el nivel 2.

En resumidas cuentas, podemos deducir que el relleno sedimentario del Abrigo del Molino, se ha generado de una manera relativamente rápida, iniciándose con posterioridad a $60 \mathrm{ka}$ y colmatándose en torno a $30 \mathrm{ka}$, de manera aproximada, respondiendo a impulsos sedimentarios de distinta índole y magnitud. De este modo, se habría formado desde los momentos finales del OIS 4, hasta quedar completamente sellado, seguramente, hacia el final del OIS 3, e incluso inicios del OIS 2. Por esta razón, podemos concluir que estamos ante una secuencia cronoestratigráfica de gran valor para analizar la evolución del OIS 3 en el interior de la península ibérica, ya que la completa y variada estratigrafía del Abrigo del Molino se circunscribe, casi exclusivamente, a este periodo.

\section{Las evidencias de actividad humana}

Aunque el proceso de excavación y de estudio no ha concluido, los restos que hemos recuperado hasta el momento nos indican que el Abrigo del Molino fue habitado por grupos neandertales durante tres momentos diferentes: nivel 2 (especialmente la unidad D), nivel 3 (sobre todo la unidad G) y unidad K. De este modo, los datos de industria lítica y fauna analizados hasta la fecha ofrecen ya una interesante información sobre la ocupación del yacimiento, presentando además algunas particularidades que es necesario destacar. Estos datos fueron obtenidos en las campañas de 2013-2015, y en ambos casos provienen de los niveles 2 y 3 . Los escasos restos líticos y faunísticos obtenidos del perfil en el nivel $K$, son insuficientes aún para realizar cualquier valoración por el momento, más allá de su adscripción genérica al Musteriense.

Las cadenas operativas líticas analizadas en ambos niveles presentan bastantes semejanzas, y aunque se trata de datos provisionales, es más numerosa la colección del nivel $3(\mathrm{~N}=>700)$, donde aproximadamente el $58 \%$ de las piezas son menores de 2 $\mathrm{cm}$, que la del nivel $2(\mathrm{~N}=160)$, donde este porcentaje alcanza el $70 \%$. Los métodos de talla presentes en ambos niveles presentan varios indicios (sobre todo el 3) de su correspondencia con otros yacimientos musterienses cercanos, predominando los métodos discoide y Levallois.

Por su parte, en el nivel 3 hay varias piezas que evidencian distintos componentes y etapas de los procesos de talla (percutores, yunques, núcleos, úti- 
les, lascas, debrises y productos de avivado de diferente tipo) que indican la realización de labores de talla dentro del abrigo. El utillaje identificado está compuesto por pocas piezas, fundamentalmente denticulados y escotaduras, destacando también la presencia de cantos tallados.

En cuanto a la captación de materias primas, en su mayor parte se trata de rocas fácilmente localizables en los aluviones del río Eresma, por lo que esta tiene un carácter inmediato. No obstante, algunos de los materiales silíceos utilizados no proceden de un entorno próximo, lo cual nos hace pensar en estrategias de movilidad y captación más complejas, donde se combina la explotación preferente del entorno con una planificación logística de movilidad a media y larga distancia, dentro de un territorio más amplio. En este punto es interesante reseñar la utilización de distintos tipos de rocas y materiales silíceos, en función del tipo de cadena operativa a realizar. Así, mientras los cantos utilizados como percutores son en su práctica totalidad cantos esféricos o subesféricos muy bien redondeados, de gneis o granito, fácilmente localizables en el río; en cambio, para la elaboración de cantos tallados destinados seguramente a fracturar las diáfisis, se han seleccionado cantos aplanados de diorita (procedentes de diques tabulares de potencia decimétrica), también presentes en el río. Las cadenas operativas mayoritarias son las que se han llevado a cabo sobre materiales silíceos (jaspe, sílex y cuarzo). De ellos el cuarzo se pueden localizar fácilmente en los aluviones del Eresma, por lo que su captación también es inmediata; en lo que respecta al jaspe y al sílex, varias piezas de jaspe presentan pátinas de tipo fluvial, como superficies endurecidas por abrasión y pulido por rodadura y saltación como transporte de fondo. En cuanto al sílex, se han documentado varios tipos, aún bajo estudio, de los cuales el más abundante es el que hemos denominado "sílex de Otero" por estar el único afloramiento conocido en la localidad de Otero de Herreros, a unos 17 $\mathrm{km}$ del Abrigo del Molino. Este sílex es de origen hidrotermal-metasomático (mineralización tipo skarn), y aunque hoy en día sólo conocemos el afloramiento de Otero, es probable que se pueda localizar a lo largo de la sierra, por lo que no es extraño que el río Eresma atraviese algún cuerpo mineralizado o filón, pudiéndolo haber incorporado a su cauce, ya que varias piezas de este sílex han mostrado pátina fluvial. Por esta razón, en principio lo consideramos también como una materia prima de carácter local. El resto de variedades silíceas no muestran evidencias de pátinas fluviales, por lo que su captación, unido a su bajo porcentaje en el yacimiento y al hecho de no haber identificado la procedencia de los mismos, nos sugiere que no se corresponden con un acceso inmediato. Las materias primas, tanto en el nivel 2 como en el 3 no presentan grandes diferencias entre sí, estando documentadas en ambos niveles los mismos materiales del espectro local, razón por la cual, en principio, los patrones de captación de materias primas son muy similares en ambos contextos.

En lo que respecta a la fauna recuperada hasta el momento en los niveles $2(N=263)$ y $3(N=1290)$, en ambos niveles existe un elevado grado de fragmentación de los restos de macromamíferos, donde los fragmentos menores de $3 \mathrm{~cm}$ suponen más del $80 \%$ de la muestra; esto impide cualquier identificación taxonómica o anatómica precisa de buena parte del registro. Aunque el estado de conservación se puede considerar como excelente, la muestra presenta varias alteraciones postdeposicionales de carácter leve, como las producidas por procesos químicos o bioquímicos. Por otra parte y como ya se ha mencionado, la determinación taxonómica resulta difícil debido al elevado grado de fragmentación y la ausencia de piezas dentarias y epífisis. A pesar de todo se ha podido confirmar la presencia de al menos dos especies, Equus sp. y Cervus elaphus, que constituyen los taxones más abundantes en ambos niveles.

Por otra parte, el grado de fragmentación que presenta la fauna, unido a la notable presencia de marcas antrópicas y su asociación con una abundante industria lítica, indica un origen inequívocamente antrópico para la acumulación ósea. En los dos niveles ( 2 y 3 ) musterienses estudiados se documentan marcas de corte, descarnado o percusión siendo su porcentaje en los restos mayores de $1 \mathrm{~cm}$, de un $10 \%$. Aunque también se han documentado marcas producidas por carnívoros, su número es ínfimo, no llegando al $1 \%$ sobre el total de la muestra, y tratándose en todo caso de un acceso secundario. Por otra parte, también se han recuperado numerosos restos de microfauna, siendo el conejo el taxón dominante; en menor porcentaje también hay presencia de pequeños roedores, aves, anfibios y peces.

El elevado número de restos líticos y faunísticos que se han documentado en el nivel 3 (Fig. 10), junto con la identificación de varias actividades talla (existencia de remontajes y cadenas operativas íntegras), unido al elevado grado de antropización que presenta la fauna, nos hacen pensar en la existencia de un suelo de ocupación muy bien preservado, que se corresponde con la base del nivel 3 (unidad G). Por su parte, el número reducido de restos procedentes del nivel 2 no permiten una definición que vaya más allá de establecer su similitud con el nivel 3 y por tanto atribuir su adscripción al Musteriense derivada, principalmente, de esta circunstancia y de la cronología obtenida. 

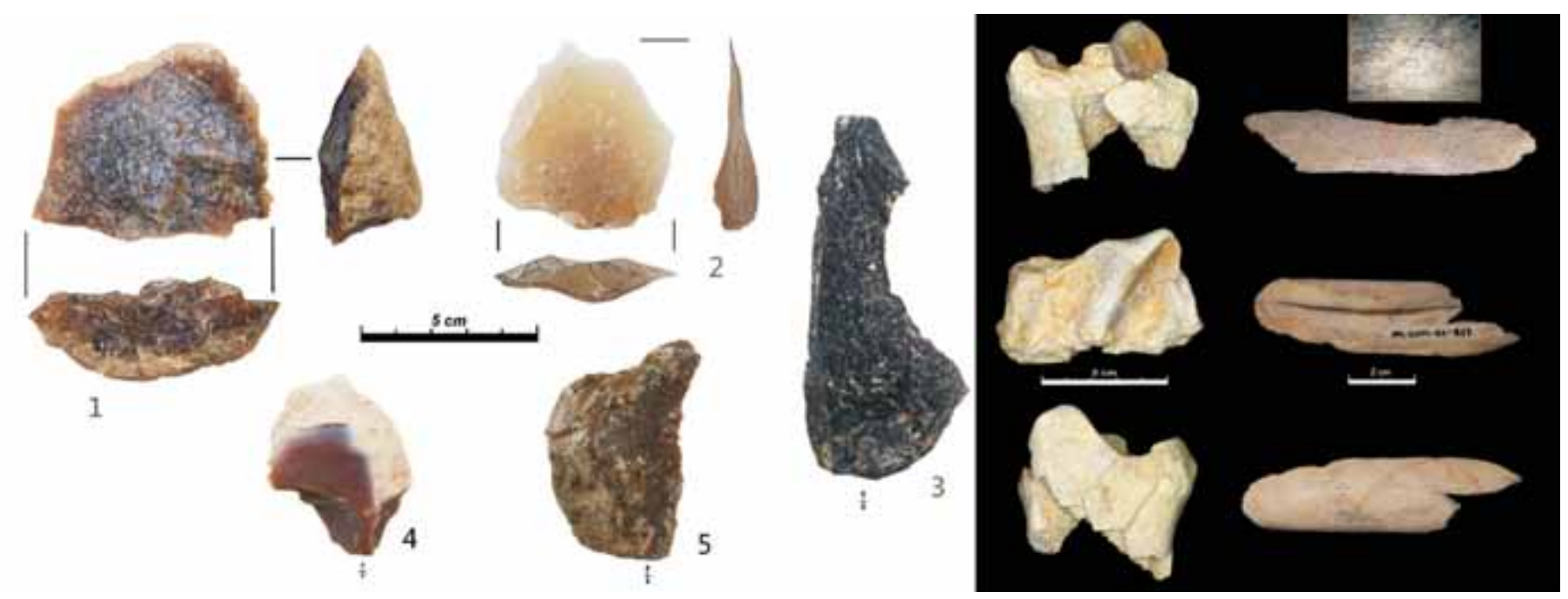

Figura 10. Industria lítica y huesos con marcas de corte y percusión, del nivel 3.

Figure 10. Lithic industry, and bones with cut and impact marks from Level 3.

\section{Otras ocupaciones paleolíticas en el valle alto del Eresma}

Hasta el descubrimiento del yacimiento del Abrigo del Molino, los únicos restos paleolíticos en el valle del Eresma se circunscribían al yacimiento achelense de Armuña (Segovia) -unos $19 \mathrm{~km}$ aguas abajo del Abrigo del Molino-, y algún otro hallazgo aislado de similar cronología ubicados en las terrazas del Eresma, también en su cauce medio (Álvarez-Alonso and Andrés-Herrero, 2014). Ya en el marco temporal del Pleistoceno superior, en el valle alto del Eresma y su entorno próximo, únicamente se conocían vestigios de tipo paleontológico, sin que se hubiera detectado -aunque parecía intuirse-, presencia humana paleolítica en esta zona.

Como ya hemos visto, las excavaciones realizadas en el Abrigo del Molino han sacado a la luz una importante secuencia musteriense, pero también, y gracias a las prospecciones y sondeos llevados a cabo desde 2013, se han podido localizar más vestigios paleolíticos en este sector del valle, en torno a la ciudad de Segovia. Estos trabajos están aún en una fase inicial, por lo que es posible que en un futuro puedan documentarse nuevos yacimientos.

\section{Abrigo del Molino superior}

Situado a una cota superior y a escasos metros del Abrigo del Molino (resalte superior en Fig. 4A), como consecuencia del mismo pliegue monoclinal que favoreció la formación este último, se localiza un aflo- ramiento rocoso completamente colmatado, en el que se intuía la existencia de un posible abrigo, o al menos cierto desarrollo hacia el interior de la visera. Como prolongación de las investigaciones llevadas a cabo en el Abrigo del Molino, en 2014 se planteó la realización de un sondeo extendiendo la cuadrícula del yacimiento, dada la cercanía entre ambos lugares y su más que posible relación. De este modo, se llevó a cabo una trinchera de aproximadamente $3 \times 1 \mathrm{~m}$, perpendicular a la visera. En 2015 la excavación se ha ampliado en extensión.

En esta zona, hasta el momento se han podido diferenciar dos niveles, además del horizonte superficial. El primero, con una potencia máxima de $1 \mathrm{~m}$, está formado fundamentalmente por clastos angulosos de pequeño y medio tamaño (entre 3 y $5 \mathrm{~cm}$ los primeros que son mayoría y algunos de mayor tamaño: centil $20 \mathrm{~cm}$ ), en una matriz de arenas amarillas, que se compacta en algunas zonas por el aporte de carbonato cálcico en la zona situada bajo la roca. En este nivel solo se recuperaron restos de microfauna.

El segundo nivel, de espesor variable, está compuesto por una matriz arenosa con bloques de dolomía con un tamaño de entre 40 y $80 \mathrm{~cm}$. En este nivel, han aparecido varios restos líticos, destacando un denticulado de cristal de roca y algunos restos de talla de esta misma materia prima; abundantes restos de macro y microfauna, entre los destacan los atribuibles al género Equus, Cervus y a la especie Lynx, sp. (Fig. 11). El taxón dominante entre la microfauna es el conejo, Oryctolagus cuniculus.

El origen antrópico de los restos de macrofauna recuperados no ofrece dudas, ya que son abundantes 
los restos óseos con marcas de corte, descarnado o percusión. Ante la falta de más datos, tanto la industria lítica como los restos óseos parecen vincular este horizonte, de manera preliminar, con la ocupación musteriense del Abrigo del Molino.

\section{Cueva de San Lázaro}

Se trata de una pequeña cavidad formada en las dolomías cretácicas de la margen izquierda del río Eresma, junto al puente del mismo nombre, a unos $500 \mathrm{~m}$ del Abrigo del Molino, aguas arriba del río Eresma, y a 15 $\mathrm{m}$ sobre su cauce (Fig. 3). Este yacimiento fue descubierto en la campaña de sondeos de julio de 2014 donde, a pesar de no existir ningún indicio de yacimiento arqueológico en superficie, se decidió practicar una calicata de $2 \times 2 \mathrm{~m}$, en la que finalmente se documentaron restos de industria lítica y fauna, que a falta de dataciones, son compatibles con las ocupaciones humanas del Abrigo del Molino (Fig. 12).

Tras un primer nivel revuelto, con mezcla de mate-

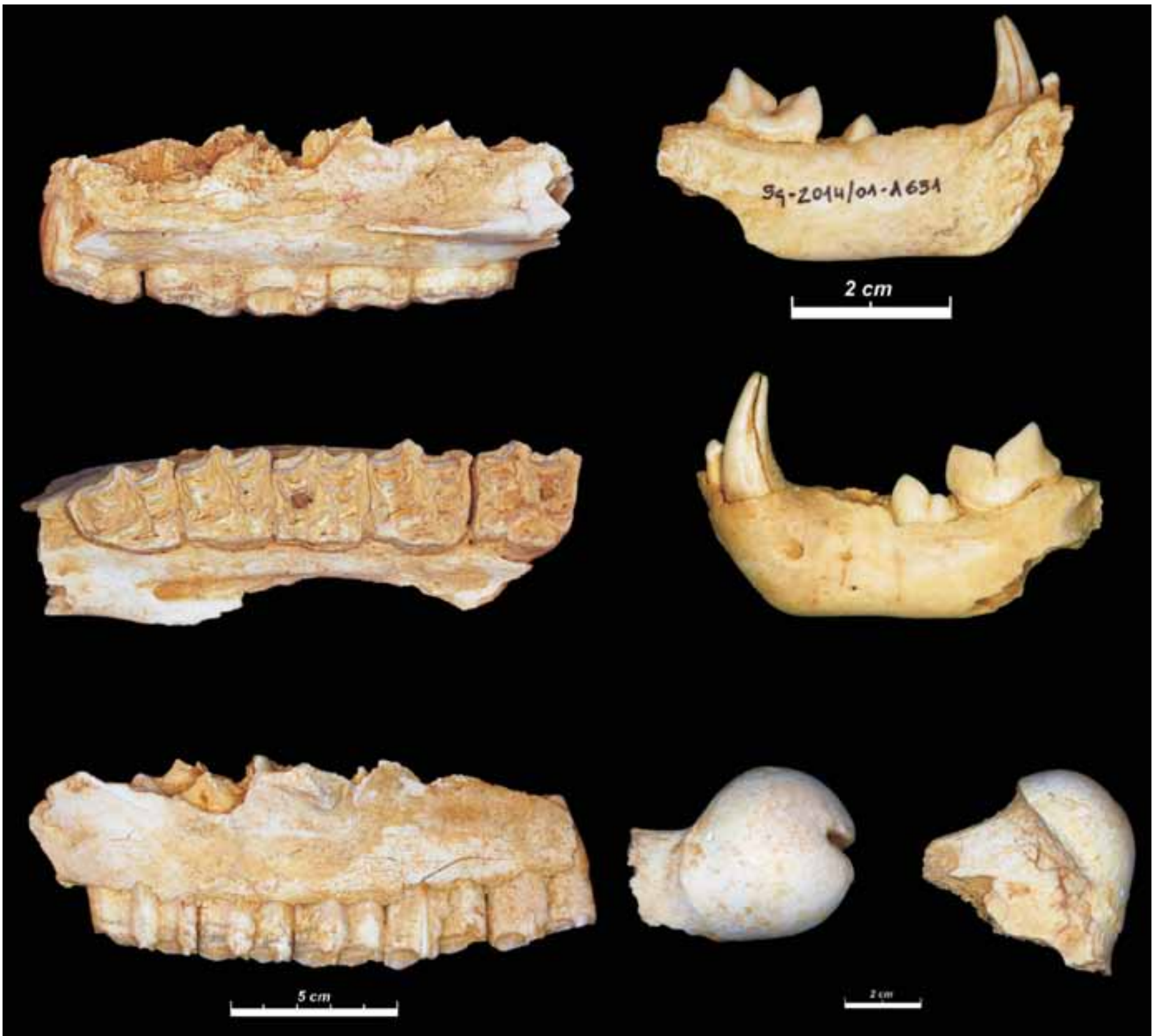

Figura 11. Restos de fauna de la zona superior del Abrigo del Molino. Figure 11. Faunal remains from the Abrigo del Molino (upper area). 


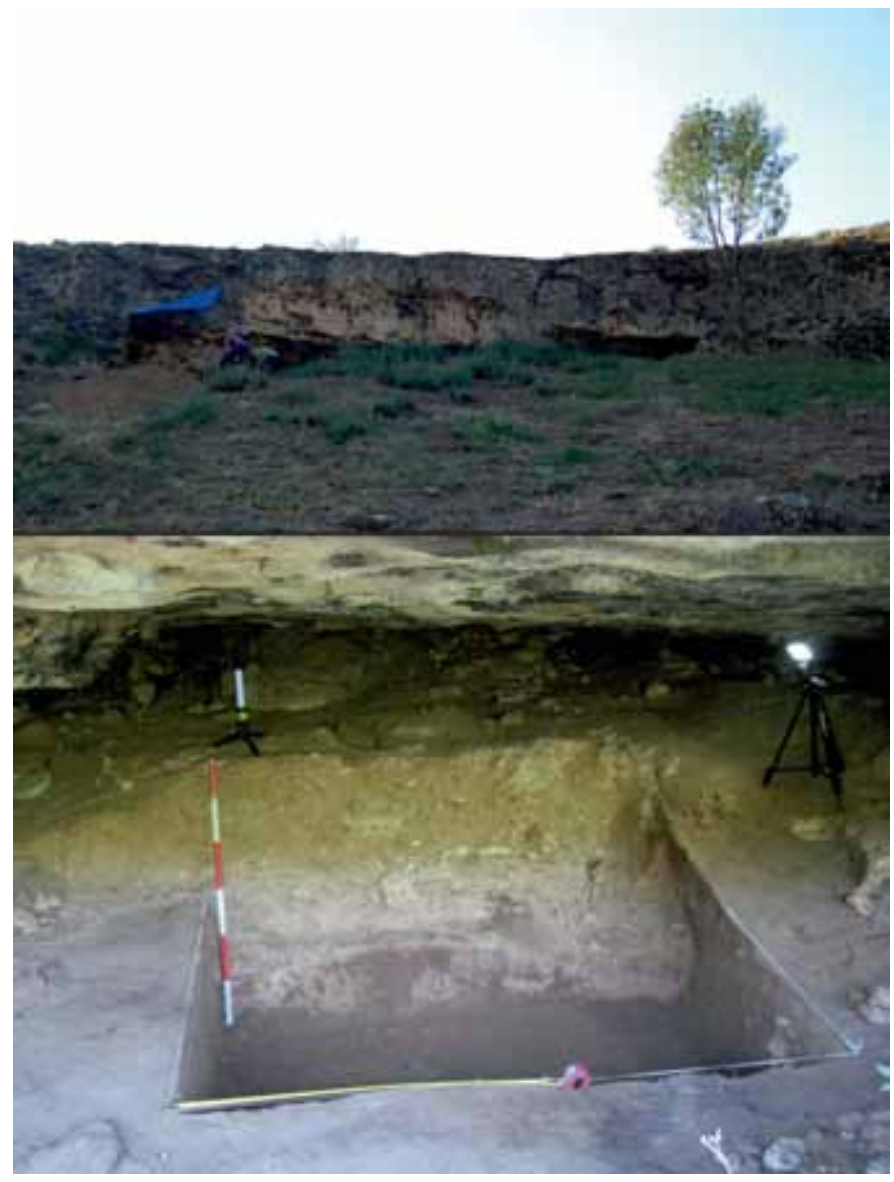

Figura 12. Cueva de San Lázaro. Arriba, vista de la entrada. Debajo, sondeo realizado en 2014.

Figure 12. The San Lázaro cave. Above, view of the entrance. Below, excavation developed in 2014.

riales modernos y restos cerámicos de adscripción prehistórica, se localiza un nivel de aspecto intacto, con abundante fauna y restos de industria lítica, entre los que destaca alguna pieza Levallois y una raedera de jaspe. En esta zona proseguiremos la excavación una vez finalizados los trabajos en el Abrigo del Molino.

\section{Materiales en superficie en las terrazas del Eresma}

Además de los sondeos arqueológicos descritos anteriormente, a lo largo de las campañas de los años 2013-2015 se han efectuado muestreos en el curso alto del río con el fin de realizar una litoteca y analizar las materias primas líticas presentes en el Abrigo del Molino. Durante estas prospecciones en el cauce se recuperó un bifaz de cuarcita, muy rodado y fracturado en su extremo distal, a unos $400 \mathrm{~m}$ del Abrigo del
Molino, aguas abajo del Eresma en uno de los numerosos aluviones existentes. Esta pieza se une a la escasa nómina de industrias adscribibles al Paleolítico inferior o medio antiguo presentes en el valle del Eresma (Fig. 1), y que vendría a apuntar la posible existencia de depósitos de esta cronología en alguna de las terrazas colgadas de este río que existen en el entorno de la ciudad de Segovia (Fig. 13).

\section{Los cubiles de hiena}

En el entorno del Abrigo del Molino, tanto en el valle del Eresma, como en los de sus afluentes, el Clamores y el Tejadilla, se localizan distintos yacimientos paleontológicos, que han sido estudiados a partir de la década de 1980, e interpretados como cubiles de hiena. Estos depósitos paleontológicos, pertenecientes al Pleistoceno superior, son de gran importancia para poder evaluar los ecosistemas de este período contemporáneos de las ocupaciones humanas en el Abrigo del Molino. Ubicados en las dolomías cretácicas, algunos de ellos han sido excavados de una manera sistemática, contando con dataciones radiocarbónicas, además de estudios políni$\cos$ y arqueozoológicos (taxonómicos, tafonómicos, etc...), que aportan interesante información para reconstruir el paleoambiente del valle alto del Eresma, y así contextualizar las ocupaciones humanas musterienses.

La cueva del Búho y su contigua La Zarzamora, están ubicadas en el valle del arroyo Tejadilla, a poco más de $2 \mathrm{~km}$ de distancia del Abrigo del Molino (Fig. 3). La primera fue excavada en la década de 1980 (Molero et al., 1989; Íñigo et al., 1998) y la segunda entre los años 2008 y 2013 (Sala et al., 2010, 2011).Ambos yacimientos, que en realidad son parte del mismo sistema kárstico, han sido interpretados como cubiles de hiena, pertenecientes a la segunda mitad del OIS 3 (Arribas et al., 2008). Gracias a los restos exhumados en estas dos excavaciones, podemos tener una idea suficientemente clara del entorno paleoambiental en ese período concreto, resultados que se pueden completar con los obtenidos hasta la fecha en el Abrigo del Molino. En el Búho y la Zarzamora, los ungulados están dominados por dos especies de caballo: Equus hydruntinus y Equus ferus, siguiéndoles en importancia los grandes bóvidos: Bison priscus y Bos primigenius, Cervus elaphus, Sus scrofa, con presencia de rinoceronte, en este caso Stephanorhinus hemitoecus. Los carnívoros están dominados por las hienas, como es normal en estos espacios, contando con presencia, aunque menor, de cánidos (Vulpes vulpes y Canis lupus), félidos 

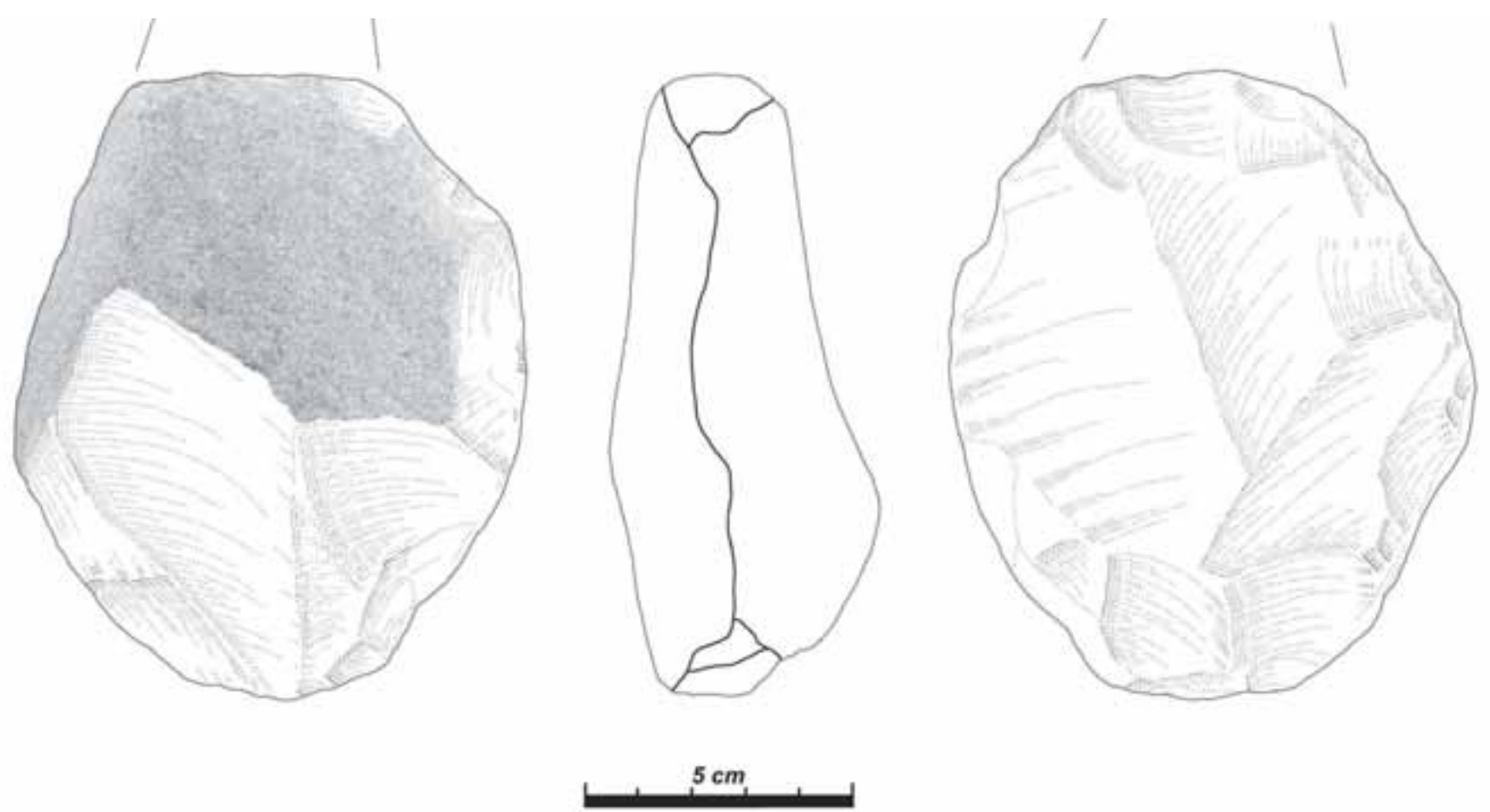

Figura 13. Bifaz hallado en un aluvión del río Eresma cerca del Abrigo del Molino.

Figure 13. Hand axe found in the banks of the Eresma river, near the Abrigo del Molino.

(Panthera pardus y Lynx, sp.) y un mustélido (Meles meles) (Molero et al., 1989, Íñigo et al., 1998, Arribas et al., 2008; Sala et al., 2010, 2011).

Esta asociación faunística, junto con la representada por los micromamíferos -entre los que se cuentan varias especies de roedores de los géneros Microtus, Arvicola y Apodemus, así como topos y lagomorfosademás de los datos polínicos obtenidos, indican la existencia de grandes zonas abiertas en este espacio, dominadas por las especies de herbáceas, combinadas con reductos boscosos, seguramente asociados a los cauces fluviales (bosques-galería). Este tipo de medios serían muy apropiados para la diversa nómina de macromamíferos presentes en estos yacimientos (Sala et al., 2011).

Frente a las cuevas del Buho y La Zarzamora, está el Portalón del Tejadilla, una cueva de mayores dimensiones en la que también se ha identificado una asociación faunística con similitudes a las anteriores y presencia de crocuta crocuta, que sugieren que se trata también de un cubil de hienas (Sanz et al., 2015).

Más cerca aún del Abrigo del Molino, a unos $800 \mathrm{~m}$ de distancia, se localizan otra serie de cubiles de hiena ubicados en el valle del Clamores, en un entorno también kárstico: Pinarillo 1, 2 y 3 (Fig. 3). En estos enclaves se ha constatado una presencia continua de hiénidos (Crocuta crocuta) sin haberse detectado ocupación humana en ninguno de ellos. La asociación faunística, aunque mayor, es muy similar a la observada en las cuevas del Búho y de la Zarzamora. Además de todos los taxones citados, estos yacimientos cuentan con restos de Panthera leo spelaea, entre los félidos, y de Mustela nivalis, y aunque no contamos con dataciones numéricas han sido adscritos a la primera mitad del Pleistoceno superior (Arribas et al., 2008), siendo compatibles en parte con el espectro cronológico del Abrigo del Molino superior.

En todos estos enclaves destaca una circunstancia, la existencia en el mismo entorno de hienas y otros grandes carnívoros además de humanos, ocupando todos ellos espacios bien diferenciados pero muy cercanos, ya que en el Abrigo del Molino no se ha registrado ninguna evidencia que nos indique su ocupación por parte de carnívoros, ni una posible alternancia en la ocupación; al igual que sucede con los cubiles de hiena, donde no se registran evidencias antrópicas.

\section{Conclusiones}

En primer lugar, las investigaciones geoarqueológicas del Abrigo del Molino han servido, durante los dos primeros años de investigación, para poner al descubier- 
to una rica secuencia de niveles que cubre la práctica totalidad del OIS 3, incluyendo tres niveles con ocupación humana. Estos resultados son de gran valor para analizar el final de las ocupaciones neandertales en el interior peninsular, así como para obtener, por vez primera, datos de contexto que nos puedan ayudar a establecer una cronoestratigrafía de las terrazas del alto Eresma, gracias a la existencia de niveles de paleoinundación en la base de la secuencia, primeros depósitos conocidos de este tipo en este valle (Díez Herrero et al., 2014). Por otra parte se constata la importancia de este sector del valle del Eresma para el estudio de las ocupaciones musterienses en el interior peninsular, con al menos tres yacimientos de esta cronología en contexto kárstico, identificados desde 2012.

La importancia del Abrigo del Molino no sólo radica en su posición geográfica, en un área donde previamente no había indicios de ocupación musteriense en ambientes kársticos, sino también en las excepcionales condiciones de preservación del yacimiento. Probablemente la existencia de un entorno que cuenta con una amplia variedad de biotopos propició la frecuentación del valle alto del Eresma por los grupos neandertales durante el OIS 3. La existencia de tres horizontes de ocupación, bien definidos y separados por hiatos, sobre los que se ha realizado un exhaustivo análisis cronoestratigráfico, permitirá correlacionar de una manera más precisa el resto de hallazgos existentes que se vayan produciendo en el entorno inmediato y de los que se empieza a tener alguna información; y cuyo objetivo es realizar una reconstrucción del poblamiento neandertal durante el Pleistoceno superior en el centro de la península Ibérica. Los niveles indentificados en el Abrigo del Molino parecen corresponderse con ocupaciones cortas y temporales, seguramente esporádicas pero lo suficientemente recurrentes como para plantear posibles patrones de movilidad y estacionalidad, en los cuales el valle del Eresma juega un papel intermedio entre rutas de paso, o tránsito, entre distintos puntos del interior peninsular.

Hasta que se produjo el descubrimiento del Abrigo del Molino, la zona comprendida entre el valle del Duero y el Sistema Central se mostraba como un área con muy pocos lugares conocidos de hábitat musteriense, y donde apenas se había localizado un yacimiento de esta cronología al aire libre de cierta entidad, La Estación (Álvarez Alonso and Andrés Herrero, 2011b; 2014). Al margen, existen numerosos indicios de piezas del Paleolítico medio halladas al aire libre, que en su mayor parte se encuentran descontextualizadas (Álvarez Alonso and Andrés-Herrero, 2014; Álvarez Alonso et al., 2013b).

Tanto la secuencia cronocultural y geocronológica del Abrigo del Molino, como el resto de hallazgos que se han producido en su entorno inmediato en el transcurso de nuestras investigaciones, nos permitirán profundizar en el estudio de la evolución del medio físico y ambiental en el marco del valle del río Eresma. Aunque los datos paleoambientales aún son escasos, su correlación con los obtenidos en los yacimientos paleontológicos próximos y coetáneos (valle deTejadilla, Pinarillo, etc.), están permitiendo ya completar una de las secuencias paleogeográficas más completas del centro peninsular.

Por otra parte, las características geológicas y fisiográficas del interior de la Meseta norte condicionan que los yacimientos arqueológicos paleolíticos al aire libre sean mucho más numerosos, frente a los localizados en ambientes kársticos. Esta circunstancia contrasta con la situación de las regiones periféricas de la península ibérica, como la región cantábrica, el área levantina o el sector prepirenaico. El caso de la región cantábrica es especialmente significativo, ya que sus características geológicas y orográficas, favorecen una mayor presencia de yacimientos musterienses en cuevas, en relación a las ocupaciones al aire libre, debido a la conservación diferencial y también a la tradición investigadora, que ha venido relegando tradicionalmente la arqueología al aire libre a favor de la arqueología paleolítica en cuevas (Arrizabalaga et al., 2014). Esta circunstancia se ha reflejado en recientes trabajos sobre el Paleolítico inferior y medio en el sur del Duero y es uno de los factores que redundan en la importancia del Abrigo del Molino y su entorno (Álvarez Alonso and Andrés Herrero, 2011b; 2014).

Aunque hay numerosas evidencias de ocupación humana en tiempos paleolíticos en el interior peninsular que apuntan a su continuidad durante la primera mitad del Pleistoceno superior, resulta mucho más abundante la secuencia paleolítica de las zonas litorales (norte, mediterráneo este y atlántica), lo cual parece indicar que el poblamiento humano pleistoceno pudo tener una mayor continuidad y estabilidad en estas regiones, con respecto al interior. Del mismo modo, allí donde proliferan los medios kársticos, los yacimientos paleolíticos resultan más abundantes y prolongados en el tiempo, con unas características que parecen implicar la existencia de hábitats más recurrentes, estables y continuos.

Otro de los grandes contextos de ocupación humana en la península, sobre todo en el interior, tiene lugar en torno a las grandes cuencas fluviales, muchas de las cuales sirven de conexión entre las regiones periféricas (valles del Ebro, Duero, Tajo, Guadiana). En estos medios, sobre todo hallamos yacimientos al aire libre, seguramente fruto de ocu- 
paciones más efímeras y ligados con vías de tránsito entre distintas cuencas o áreas. El valle alto del Eresma, se encuentra en un punto estratégico dentro de este esquema donde confluyen las grandes cuencas fluviales del interior con presencia de zonas kársticas y ambientes montañosos.

Entrando al detalle de las ocupaciones del Paleolítico medio en la Meseta norte, estas se caracterizan por un elevado número de yacimientos al aire libre como Hotel California, Hundidero, Fuente Mudarra, San Quirce, Valdecampaña o La Estación (Carbonell et al., 2014, Díez Martín et al., 2008; Díez Martín, 2010; Navazo Ruiz et al, 2011;Terradillos, 2014), por citar algunos de los más significativos. Junto a estos, se localizan unos pocos yacimientos en entornos kársticos situados, fundamentalmente, en los rebordes montañosos de la Meseta -sobre todo en la margen oriental de su cuenca, hacia el norte cantábrico y hacia el Sistema Central. Esta presencia periférica encuevas, seguramente coincide con las zonas de paso natural, la existencia de una mayor biodiversidad en esos entornos (muchos de ellos en las cabeceras o cursos medio-altos de valles fluviales), y la presencia de refugios naturales. Así, en el sur de la cordillera cantábrica, en zonas montañosas o en el pie de monte, encontramos los yacimientos de Cueva Corazón (SánchezYustos et al., 2011; Díez Martín et al., 2011) y Cueva de Guantes; en el Sistema Ibérico, en la parte oriental de la cuenca, tenemos los yacimientos de Cueva Millán (Diez Fernández et al., 2008; Roselló and Morales, 2005) o La Ermita; y en el Sistema Central, el Abrigo del Molino (Álvarez Alonso et al., 2013a; 2014a), los yacimientos de Pinilla del Valle (Arsuaga et al., 2012; Márquez et al., 2008; Baquedano et al., 2014) o Jarama VI, Los Casares y Peña Cabra (Barandiarán 1969; Alcolea et al., 1997; Kehl et al., 2013; Jordá Pardo et al., 2014) estos últimos ya en la cuenca del Tajo. La península ibérica debió de condicionar distintos esquemas de habitabilidad $y$, por lo tanto, de movilidad y estacionalidad en función de las características fisiográficas y ecológicas de cada región; este territorio interior se configura como un lugar estratégico en el tránsito de los neandertales por la península.

\section{Agradecimientos}

A todos los voluntarios que han participado en las campañas de excavación 2013, 2014 y 2015: Iván Aguilera, Juan $\mathrm{M}^{\mathrm{a}}$. Aparicio, Javier Aragoneses, Ricardo Arranz, Irantzu Bilbao, Benjamin Buffet, Margarita Castellanos, María Díaz, Lucía Expósito, Alejandro Fernández, Andrés Fernández, Tamara
Fernández, Sara de Francisco, Fernando Franco, Oscar Fuente, Eduardo García, Cristina Gómez, Oscar González, Aitor Hevia, Carlos Llave, Adara López, Roberto Madrid, Alvaro Manzanas, Beatriz Martín, Álvaro Moreno, Esther Navajo, Carla Navío, Laura Nogales, Ramón Obeso, Elvira Pastor, Uxue Pérez, Alberto Polo, Judith Puga, Rocío Rojas, Rodrigo Sierra, Irene Solano, Amalio Valles y José $\mathrm{M}^{\mathrm{a}}$ Vázquez.

A otros colaboradores con las labores de excavación y análisis, como: Nuria Sacristán y Gonzalo Lozano; Miguel Angel Luquero; Juan M. Garvía; Alicia Medialdea; Ignacio Gutiérrez Pérez.

A las instituciones y empresas patrocinadoras y colaboradoras en las campañas de excavación: Junta de Castilla y León (Consejería de Cultura y Delegación Territorial de Segovia), Diputación Provincial de Segovia, Excmo. Ayuntamiento de Segovia (Concejalías de Patrimonio y Turismo, y Empresa Municipal de Turismo), Restaurante José María, Seguros De Pablos, Carburantes Carbonero y Gasóleos San Medel.

\section{Referencias}

Alcolea, J., Balbín, R., García, M.A., García, M.A., Jiménez, P.J., Aldecoa, A., Casado, A.B., Andrés, B. de, Ruiz, S., Sainz, P. and Suárez, N. 1997. Avance al estudio del poblamiento paleolítico del Alto Valle del Sorbe (Muriel, Guadalajara). Actas del II Congreso de Arqueología Peninsular 1996, Zamora, 201-218

Álvarez-Alonso, D. and Andrés-Herrero, M. de. 2011a. Estudio geoarqueológico de las cuencas fluviales de los ríos Riaza y Duratón (Segovia): El Paleolítico inferior y medio. Informe inédito. Junta de Castilla y León.

Álvarez-Alonso, D. and Andrés-Herrero, M. de. 2011b. El Paleolítico inferior y medio en el interfluvio RiazaDuratón (Segovia). Férvedes,7, 49-56.

Álvarez-Alonso, D. and Andrés-Herrero, M. de. 2014. Las primeras ocupaciones humanas al sur del Duero: el Paleolítico inferior y medio en Segovia. Segovia Histórica, 1, 9-24.

Álvarez-Alonso, D., Andrés-Herrero, M. de, Díez-Herrero, A. and Rojo Hernández, J. A. 2013a. El Abrigo del Molino (Segovia, España). Ocupaciones neandertales en el norte del Sistema Central. El Cuaternario Ibérico: investigación en el siglo XXI, Actas de la VIII Reunión de Cuaternario Ibérico. Sevilla-La Rinconada, Sevilla, 91-94.

Álvarez-Alonso, D., Andrés-Herrero, M. de, Díez-Herrero, A. and Tanarro García, L. M. 2013b. Relación entre los yacimientos arqueológicos y la morfología fluvial durante el Paleolítico antiguo en el interfluvio Riaza-Duratón (Segovia, España). El Cuaternario Ibérico: investigación en el siglo XXI, Actas de la VIII Reunión de Cuaternario Ibérico. Sevilla-La Rinconada, Sevilla, 34-38.

Álvarez-Alonso, D., Andrés-Herrero, M. de, Díez-Herrero, A. and Rojo Hernández, J. A. 2014a. El Abrigo del Molino 
Álvarez-Alonso, D., et al., 2018. Análisis geoarqueológico de las ocupaciones... Boletín Geológico y Minero, 129 (1/2): $153-182$

(Segovia, España). Un nuevo yacimiento musteriense en el interior de la Península Ibérica. Actas de las Jornadas de Jóvenes Investigadores del Valle del Duero, Salamanca,17-29.

Álvarez-Alonso, D., Andrés Herrero, M. de, Díez Herrero, A., Rojo, J., Medialdea, A., Benito, G. and Vegas, J. 2014b. Geoarqueología del yacimiento musteriense del Abrigo del Molino (Segovia). Avances de la Geomorfología en España 2012-2014. XIII Reunión Nacional de Geomorfología, Cáceres, 446-449

Álvarez-Alonso, D., Andrés-Herrero, M. de, Díez-Herrero, A., Medialdea, A. and Rojo-Hernández, J. 2016. Neanderthal settlement in central Iberia: Geo-archaeological research in the Abrigo del Molino site, MIS 3 (Segovia, Iberian Peninsula) Quaternary International. http://dx.doi.org/ 10.1016/j.quaint.2016.05.027

Arrizabalaga, A., Ríos, J. and Álvarez-Alonso, D. 2014. The past is out there: open air Palaeolithic sites and new research strategies in the Cantabrian region (northern Iberia), Quaternary International, http://dx.doi.org/ 10.1016/j.quaint.2014.07.051

Arribas, A. Solano, J. G., Garrido, G. and Carroza, J. A. 2008. El registro diferencial de carnívoros y homínidos en los karst del Pleistoceno del Sistema Central español -condicionantes geológicos y espaciales. Zooarqueología hoy. Encuentros Hispano-Argentinos, Burgos, 39-52.

Arsuaga, J. L., Baquedano, E., Pérez-González, A., Sala, N., Quam, R. M., Rodríguez, L., García, R., Álvarez-Laó, D. J., Laplana, C., Huguet, R., Sevilla, P., Maldonado, E., Blain, H.-A., Ruíz-Zapata, B., Sala, P., Gil-García, Mª.J., Uzquiano, P., Pantoja, A. and Márquez, B. 2012. Understanding the ancient hábitats of the last-interglacial (late MIS 5) Neanderthals of central Iberia: Paleoenviromental and taphonomic evidence from the Cueva del Camino (Spain) site. Quaternary International, 275, 55-75

Baquedano, E., Márquez, B., Laplana, C., Arsuaga, J.L. and Pérez González, A. 2014. Los yacimientos de Pinilla del Valle (Madrid, España), In: Sala Ramos, R. (ed.), Los cazadores recolectores del Pleistoceno y del Holoceno en Iberia y el Estrecho de Gibraltar: estado actual del conocimiento del registro arqueológico, Burgos, pp. 577-584

Barandiarán Maestu, I. 1969. Yacimiento musteriense de la Cueva de Los Casares (Guadalajara). X Congreso Nacional de Arqueología, Mahón, 153-158.

Benito, G., Sánchez-Moya, Y. and Sopeña, A. 2003. Sedimentology of high-stage flood deposits of the Tagus river, Central Spain. Sedimentary Geology, 157, 107-132.

Campaña, I., Pérez-González, A., Benito-Calvo, A., Bermúdez de Castro, J.M. and Carbonell, E. 2013. Facies sedimentarias del yacimiento arqueo-paleontológico de Gran Dolina (Sierra de Atapuerca,Burgos), In: Baena, R., Fernández, J.J., Guerrero, I. (Eds.), El Cuaternario ibérico: investigación en el s. XXI, Sevilla, pp. 290-292.

Carbonell, E., Huguet, R., Cáceres, I., Lorenzo, C., Mosquera, M., Ollé, A., Rodríguez, X.P., Saladié, P., Vergés, J.M., García-Medrano, P., Rosell, J., Vallverdú, J., carretero, J.M., Navazo, M., Ortega, A.I., Martinón, M., Morales, J.I., Allué, E., Aramburu, A., Canals, A., Carrancho, A.,
Castilla, M., Expósito, I., Fontanals, M., Francés, M., Galindo, M., García-Antón, D., García, N., Gracia, A., García, R., Gómez-Merino, G., Iriarte, E., LomberaHermida, A., López-Polín, L., Lozano, M., Van der Made, J., Martínez, I., Mateos, A., Pérez-Romero, A., Poza, E., Quam, R., Rodríguez Hidalgo, A., Rodríguez, J., Rodríguez, L., Santos, E., Terradillos, M., Bermúdez de Castro, J.M. and Arsuaga, J.L. 2014. Los yacimientos arqueológicos de la Sierra de Atapuerca, In: Sala Ramos, R. (Ed.), Los cazadores recolectores del Pleistoceno y del Holoceno en Iberia y el Estrecho de Gibraltar: estado actual del conocimiento del registro arqueológico, Burgos, 534-560

Díez Fernández, C., Alonso, R., Bengoechea, A., Colina, A., Jordá, J.F., Navazo, M., Ortíz, J.E., Pérez, S. and Torres, T. 2008. El Paleolítico medio en el valle del Arlanza (Burgos) Los sitios de La Ermita, Millán y La Mina. Cuaternario y Geomorfología, 22(3-4), 135-157.

Díez-Herrero, A. and Martín-Duque, J.F. 2005. Las raíces del paisaje. Condicionantes geológicos del territorio de Segovia. In: Abella Mardones, J.A.; Salinas, B. and Yoldi, L. (Coords.) Colección Hombre y Naturaleza, VII, Junta de Castilla y León, Salamanca, 464 pp.

Díez-Herrero, A., Álvarez-Alonso, D., Andrés-Herrero, M. de, Benito, G., Rojo, J., Medialdea, A. and Vegas, J. 2014: Pleistocene flood deposits at the Abrigo del Molino archaeological site (Segovia, Central Spain). Hydrological extreme events in historic and prehistoric times (HEX 2014), Bonn, 58.

Díez-Martín, F. 2000. El poblamiento paleolítico en los páramos del Duero, Servicio de publicaciones de la Universidad de Valladolid, Valladolid, $521 \mathrm{pp}$.

Díez-Martín, F. 2010. Evaluating the effect of plowing on the archaeological record: The early middle palaeolithic in the river Duero basin plateaus (north-central Spain). Quaternary International, 214 (1-2), 30-43

Díez-Martín, F., Sánchez, P., Gómez González, J. A. and Gómez de la Rúa, D. 2008. Earlier Palaeolithic Settlement Patterns: Landscape Archaeology on the river Duero Basin Plateaus (Castilla y León, Spain). Journal of World Prehistory, 21, 103-137

Díez-Martín, F., Sánchez, P., Gómez, J. A., Gómez de la Rúa, D., Yravedra, J. and Díaz, I. 2011. La ocupación neandertal en el cañón de la Horadada (Mave, Palencia, España): nuevas perspectivas arqueológicas en Cueva Corazón. Munibe, 62, 62-85

Fernández García, P. 1987. Geomorfología del sector comprendido entre el Sistema Central y el Macizo de Santa María La Real de Nieva (Segovia). Tesis Doctoral, Universidad Complutense de Madrid, Madrid, 336 pp.

Fernández, P. 1988. Evolución cuaternaria y sistemas de terrazas en la subfosa terciaria de Valverde del Majano y el Macizo de Santa María la Real de Nieva (Segovia). Boletín de la Real Sociedad Española de Historia Natural (Sección Geológica), 84(1-2), 69-83.

Gil, J., García-Hidalgo, J.F., Segura, M., López Olmedo, F., García, A., Díaz de Neira, J.A., Montes, M. andNozal, F. 2010. El Cretácico del Sistema Central (España): Registroestratigráfico, contextodeposicional y esquemaevolutivo. Boletín de la Real Sociedad Española de Historia Natural (Sección Geológica), 104, 15-36. 
Goldberg, P. andMacphail, R. I. 2006. Practical and Theoretical Geoarchaeology. Blackwell Publishing, Malden-Oxford-Carlton.455 pp.

Iñigo, C., Molero, G. and Maldonado, E. 1998. Los carnívoros del yacimiento pleistoceno de Cueva del Búho (Segovia, España) y sus huellas de actividad. Estudios Geológicos, 54, 65-73.

Jordá, J. F., Navazo, M. and Díez Fernández-Lomana, J. C. 2014. Jarama VI (Valdesotos, Guadalajara, Castilla-La Mancha), In: Sala Ramos, R. (ed.), Los cazadores recolectores del Pleistoceno y del Holoceno en lberia y el Estrecho de Gibraltar: estado actual del conocimiento del registro arqueológico, Burgos, pp. 531-533

Kehl, M., Burow, CH., Hilgers, A., Navazo, M., Pastoors, A., Weniger, G.-Ch., Wood, R. and Jordá Pardo, J. F. 2013. Last Neanderthals at Jarama VI (central Iberia)?.Quaternary Researchhttp://dx.doi.org/10.1016/ j.yqres.2013.06.010

Martínez-Salanova, J., Olmo, A. del, and Pedraza, J. 1991. Mesozoico, Terciario y Cuaternario. In: ITGE (1991), Hoja 483 (18-19) Segovia (mapa y memoria), Mapa geológico de España, Escala 1:50.000, Segunda Serie, Instituto Tecnológico Geominero de España, Madrid. 135 pp.

Márquez, B., Mosquera, M., Panera, J., Bárez, S., Rus, I., Gómez, J. and Arsuaga, J. L. 2008. El poblamiento humano antiguo en el valle alto del Lozoya (Madrid). Espacio, Tiempo y Forma. Serie I. Nueva época. Prehistoria y Arqueología, 1, 25-32.

Molero, G., Maldonado, E., Iñigo, C., Sánchez, F. L. and Díez, A. 1989. El yacimiento del Pleistoceno superior de la Cueva del Búho (Perogordo, Segovia) y su fauna de vertebrados. Resúmenes de comunicaciones de las $V$ Jornadas de Paleontología, Valencia 101-102.

Molinero Pérez, A. 1971.Aportaciones de las excavaciones y hallazgos casuales (1941-1959) al Museo Arqueológico de Segovia. Excavaciones Arqueológicas en España, 71, Madrid, $167 \mathrm{pp}$.

Navazo, M., Alonso-Alcalde, R., Benito-Calvo, A., Díez, J.C., Pérez-González, A. and Carbonell, E. 2011. Hundidero: MIS 4 open air Neanderthal occupations in Sierra de Atapuerca. Archaeology Ethnology \& Anthropology of Eurasia, 39 (4), 29-41.

Rodríguez de Tembleque, J. 2005. Industrias achelenses en el Sudeste de la Submeseta norte y su borde meridional.Los yacimientos paleolíticos de Torralba y Ambrona (Soria). Un siglo de investigaciones, Zona Arqueológica, 5, 334-350.
Rodríguez de Tembleque, J. 2008. Primeras ocupaciones humanas en la Meseta española. Estudio geoarqueológico de depósitos fluviales en la cuenca media del Tajo, Tesis Doctoral, Universidad Autónoma de Madrid.

Rodríguez deTembleque, J., Santonja Gómez, M. and PérezGonzález, A. 1998. La ocupación humana en el Sudeste de la Meseta Norte y en el entorno de Ambrona y Torralba durante el Pleistoceno Medio.Zephyrus,51, 1934.

Roselló Izquierdo, E. and Morales Muñiz, A. 2005. Ictiofaunas musterienses de la Península Ibérica: ¿Evidencias de pesca Neandertal?. Munibe, 57, 183-195.

Sala, M.T. N., Pantoja, A., Arsuaga, J. L. and Algaba, M. 2010. "Presencia de bisonte (Bison priscus Bojanus, 1827) y uro (Bos primigenius Bojanus, 1827) en la cueva del Búho y de la Zarzamora (Segovia, España)", Munibe, 61, 43-55.

Sala, M.T. N., Arsuaga, J. L., Laplana, C., Ruiz Zapata, M. B., Gil García, M. J., García, N., Aranburu, A. and Algaba, M. 2011. Un paisaje de la Meseta durante el Pleistoceno superior. Aspetos paleontológicos de la Cueva de la Zarzamora (Segovia, España). Boletín de la Real Sociedad Española de Historia Natural. Sección geológica, 105, 1-4, 67-85.

Sánchez-Yustos, P., Díez-Martín, F., Díaz-Muñoz, I., Gómez de la Rúa, D. and Gómez González, J. A. 2011. Estrategias de talla en Cueva Corazón (Mave, Palencia). Un yacimiento del Musteriense antiguo en las estribaciones meridionales de la Cordillera Cantábrica. Trabajos de Prehistoria, 68 (1), 51-63.

Santonja, M. and Pérez-González, A. 2000-2001. EL Paleolítico inferior en el interior de la Península Ibérica. Un punto de vista desde la geoarqueología,. Zephyrus, 53-54, 27-77.

Sanz, A., Sala, N., Algaba, M. and Arsuaga, J. L. 2015. El Portalón del Tejadilla, nueva ventana al Pleistoceno superior de la Meseta castellana. Libro de resúmenes de la XXI Bienal de la Real Sociedad Española de Historia Natural. 28-29.

Terradillos, M., Díez Fernández, J.C., Jordá Pardo, J. F., Benito-Calvo, A., Clemente, I. and Hilgers, A. 2014. San Quirce (Palencia, España), un yacimiento del Paleolítico medio en la meseta norte, In: Sala Ramos, R. (Ed.), Los cazadores recolectores del Pleistoceno y del Holoceno en Iberia y el Estrecho de Gibraltar: estado actual del conocimiento del registro arqueológico, Burgos, pp. 584-586.

Recibido: marzo 2015

Revisado: junio 2015

Aceptado: febrero 2016

Publicado: marzo 2018 
